\title{
An Exploration of the Transition of Patients from Intensive Care to the Ward Environment: A ward Nursing Perspective
}

\author{
by
}

Sandra Bunn

A thesis submitted to the Victoria University of Wellington in partial fulfilment of the requirements for the degree of Masters of Nursing (Clinical)

Victoria University of Wellington 2007 


\section{Abstract}

Background: The transition of patients from intensive care to the ward environment is a regular occurrence in intensive care. Today patients are often transferred earlier and sicker due to the demands for intensive care beds. This results in patients with higher acuity being cared for in the wards. Here ward nurses have to meet the ongoing complex demands of caring for higher acuity patients, alongside managing high patient-to-nurse ratios, staffing concerns, and varying levels of experienced nurses.

Objective: This research explored the experiences of ward nurses receiving patients transferred from intensive care. The aims were to identify any areas of concern, highlight specific problems that occur on transition and to address what information is pertinent to ward nurses when receiving patients from intensive care.

Methodology: A qualitative descriptive methodology using focus groups was utilised to gather information about these experiences. Three focus groups were held with ward nurses from various wards within the study setting hospital. All participants had considerable contact with intensive care and were familiar with the processes of transferring patients.

Findings: Five themes emerged from the focus groups - Patients as intensive care staff say they are; Time to prepare the biggest thing; Documentation as a continuation of patient care; They forget what its like; and Families, a need to know about them. The theme Patients as intensive care staff say they are relates to reliable information sharing focused on the patient, their needs and condition. Participants expressed their concern that patients were not always in the condition that the intensive care staff stated they were on the referral. 
Having adequate time to prepare was considered important for the majority of ward nurses receiving patients from intensive care. Documentation was highlighted in the theme Documentation as a continuation of patient care particularly in relation to fluid balances and vital sign history. The theme They forget what its like suggests there is a perception that intensive care nurses have a lack of understanding of what the ward staff can actually manage. Decreased staffing levels during certain shift patterns and a lack of appropriately experienced staff on the wards is a common concern for ward nurses. Ward nurses also recognised that caring for families was part of their role. Patients and families may respond differently to the transfer process and their inclusion in transfer planning was seen as essential. Communication was a reoccurring element throughout all themes.

Conclusion: Communication is the paramount factor that impacts on a 'smooth transition' for ward nurses. A 'smooth transition' refers to the transfer of patients from intensive care to the next level of care. Subsequently, nurses’ perceptions need to change, whereby transfer planning from ICU should be the focus rather than discharge planning. Transfer planning and education for all nursing staff is vital if the transfer process is to be improved. Consequently, transitional care within the context of ICU aims to ensure minimal disruption and optimal continuity of care for the patient. The knowledge gained from this research may provide better understanding of the multifaceted issues linked with transitional care that may be adapted for a wider range of patients in various clinical environments. 


\section{Acknowledgements}

The author would like to thank the following people for the help, support and encouragement in completing this thesis as part of my Masters in Nursing (Clinical).

Ken Walsh - primary supervisor (for his ongoing faith, patience and encouragement)

Jan Duke - second supervisor

$>$ Chris Walsh - for stepping in on behalf of Jan

My family and friends for their ongoing support throughout this journey 


\section{Table of Contents}

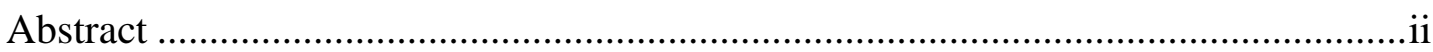

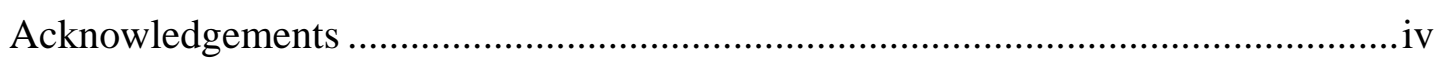

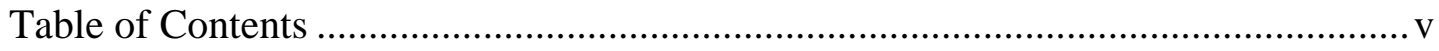

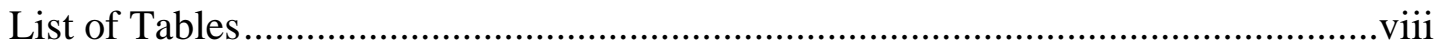

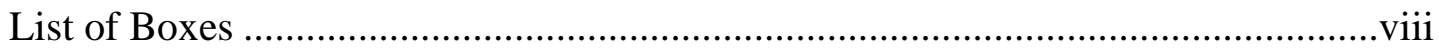

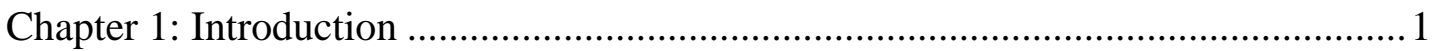

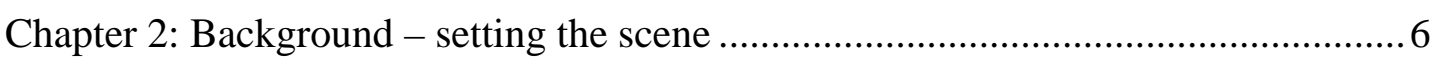

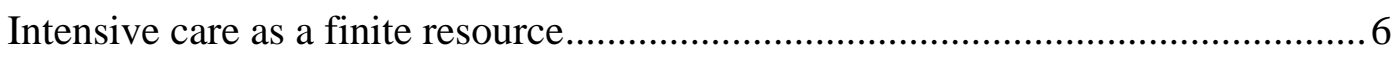

Admission/discharge/triage criteria............................................................ 11

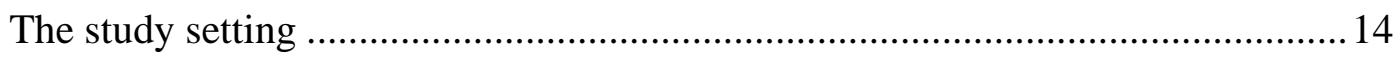

Study hospital’s ICU admission/discharge/triage criteria ................................15

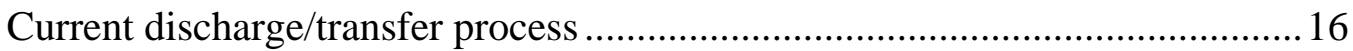

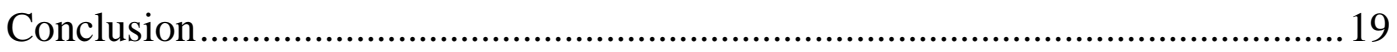

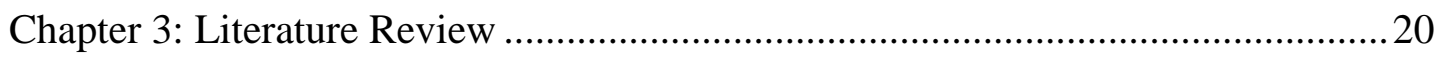

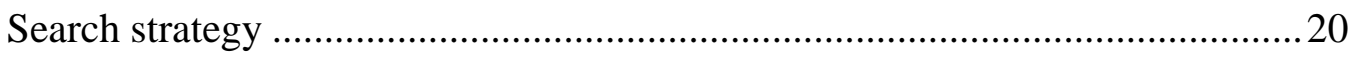

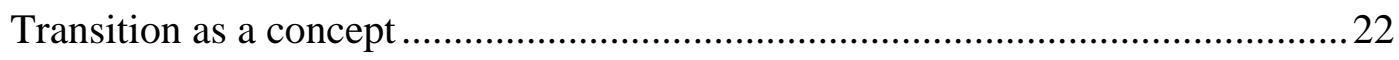

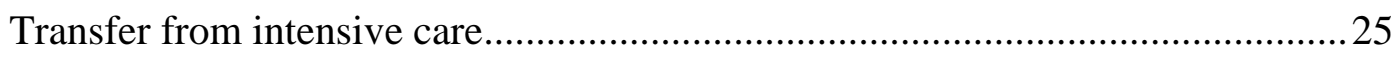

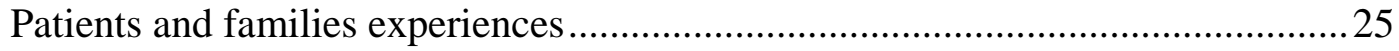

Discharge/transfer from intensive care ................................................................. 30

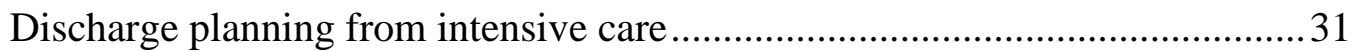

Factors that enhance or impede discharge planning......................................... 34

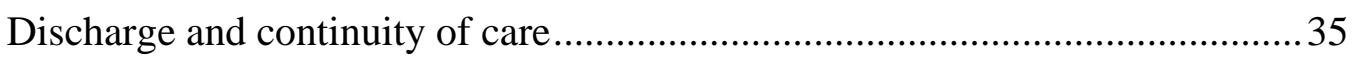

Transfer from intensive care: The ward nurses’ experience ................................36

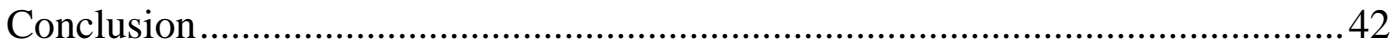

Chapter 4: Research Framework, Methodology and Methods...................................45

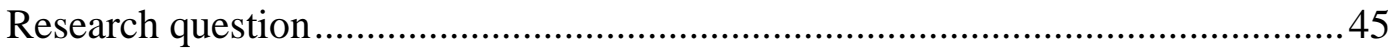

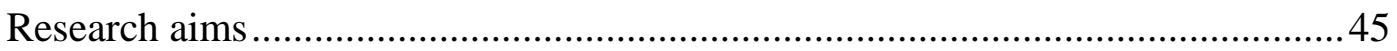

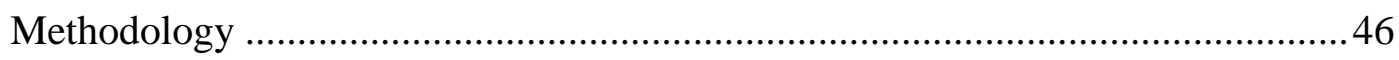

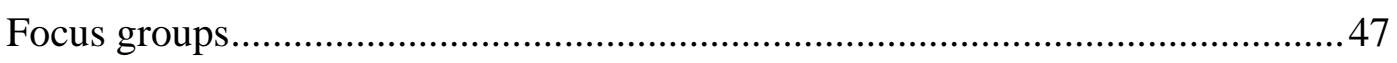

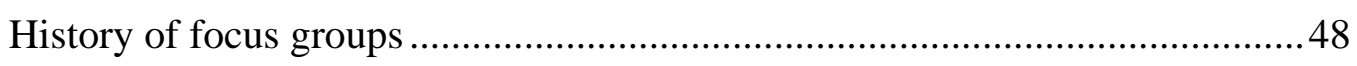

Advantages and disadvantages of focus groups ..............................................49 


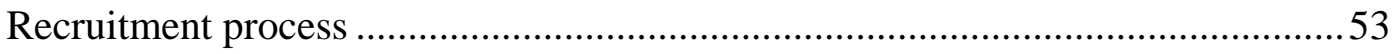

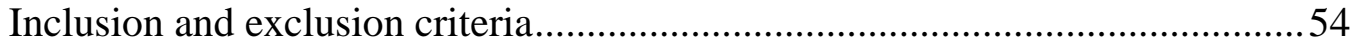

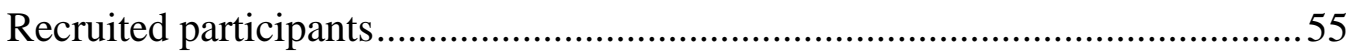

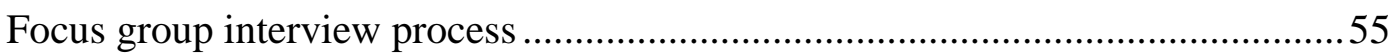

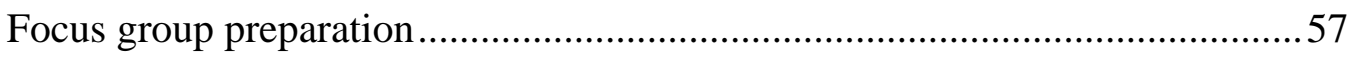

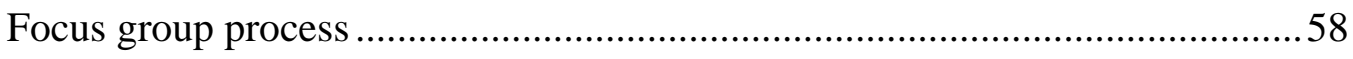

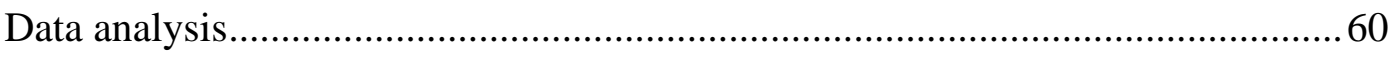

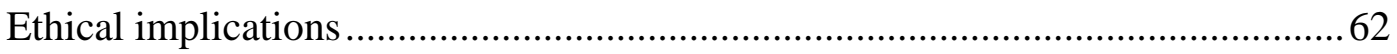

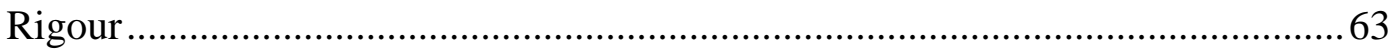

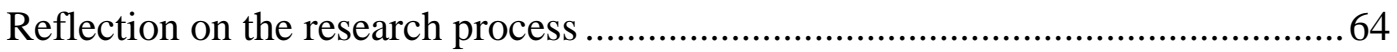

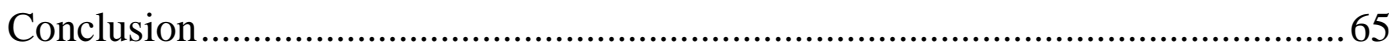

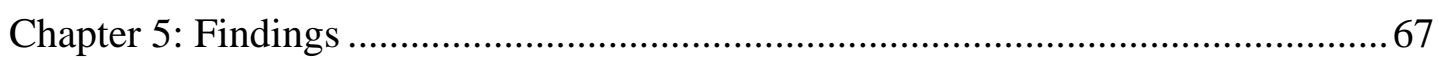

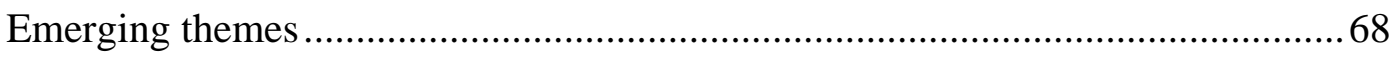

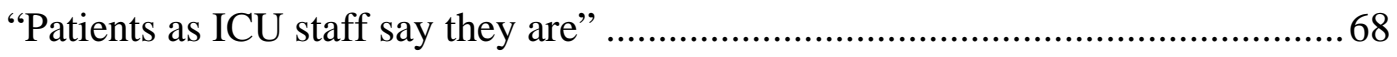

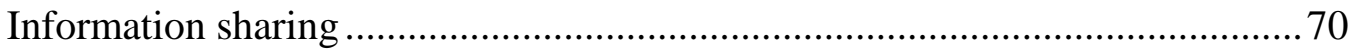

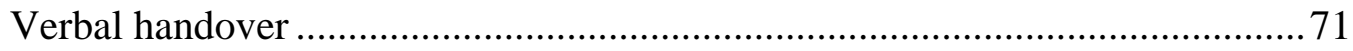

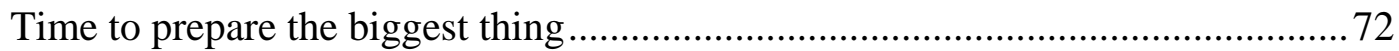

Documentation as a continuation of patient care .............................................. 76

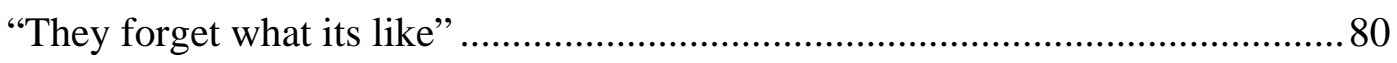

Families a need to know about them ............................................................... 82

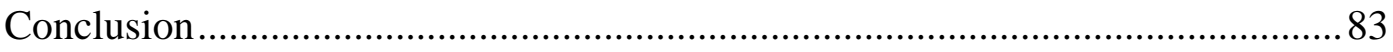

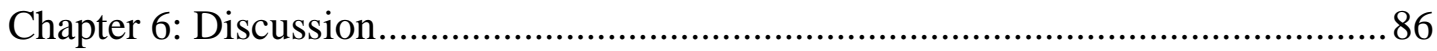

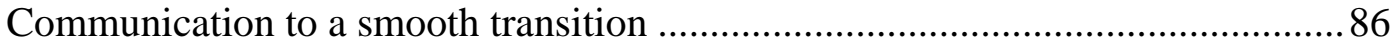

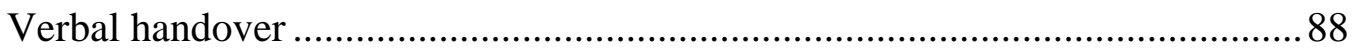

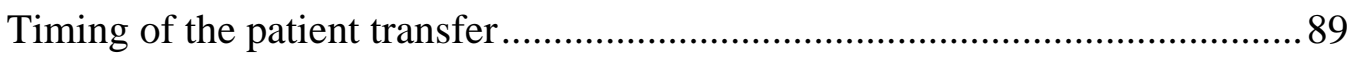

Preparing to receive intensive care patients ...................................................90

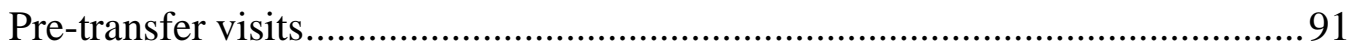

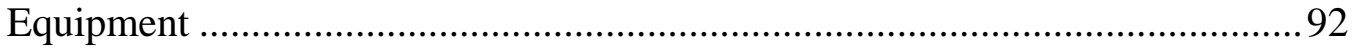

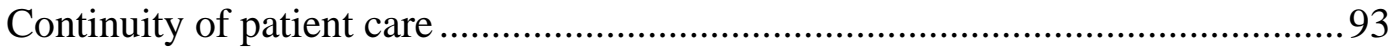

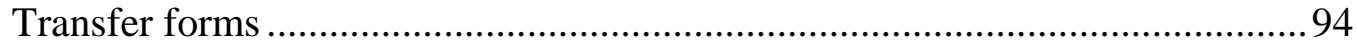

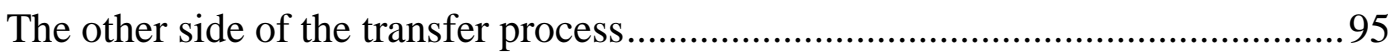

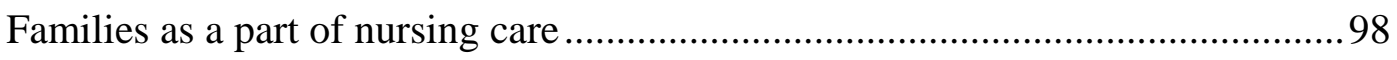

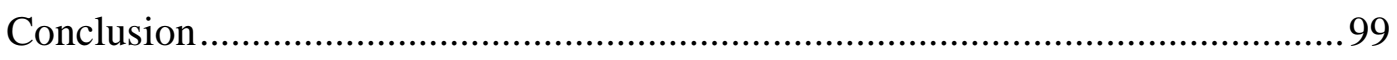

Chapter 7: Conclusion and Recommendations .................................................... 103 
Recommendations for clinical practice ......................................................... 105

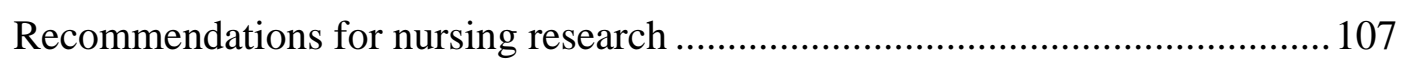

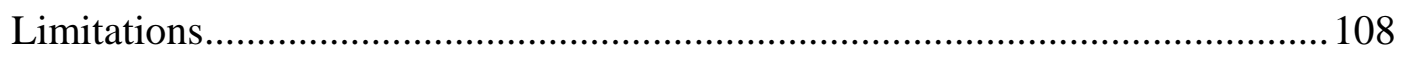

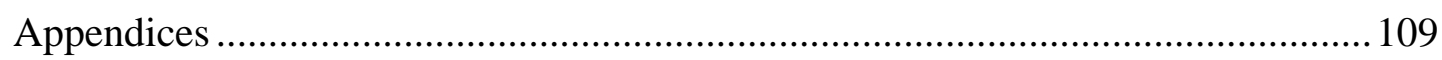

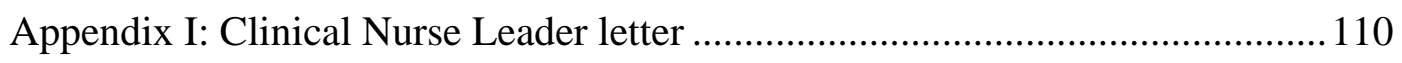

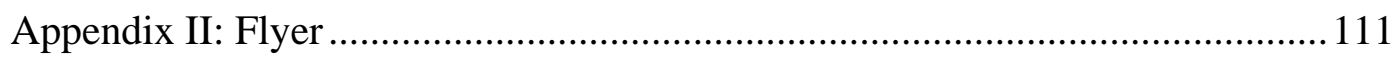

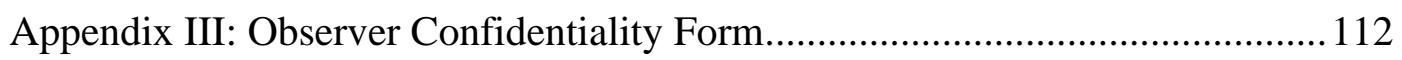

Appendix IV: Information Sheet/Consent form ..................................................113

Appendix V: Northern Y Regional Ethics Committee....................................... 116

Appendix VI: Kaumatua Kaunihera Committee ............................................... 117

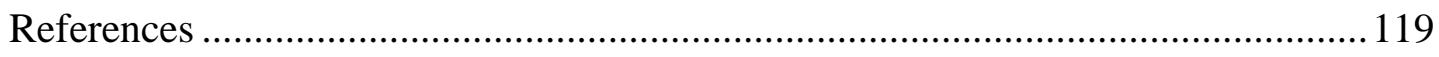




\section{List of Tables}

Table 1: Available Beds/100,000 between 2000/2001 and 2002/2003.......................9

Table 2: Ventilator Beds/100,000 between 2000/2001 and 2002/2003 ......................9

Table 3: Advantages and Disadvantages of Focus Groups ........................................51

\section{List of Boxes}

Box 1: Headings in General Transfer Form..................................17 


\section{Chapter 1: Introduction}

The changing role of the acute care hospital impacts radically on the flow of patients within the hospital system, resulting in inefficient, disorganised patient movement and the creation of gaps in patient care (Benner, Hooper-Kyriakidis, \& Stannard, 1999). No more so is this apparent than the transfer of patients from the Intensive Care Unit (ICU) to the ward, where patients are transferred earlier and sicker due to the demand for intensive care beds. The transfer of patients is a daily occurrence in an intensive care environment within an acute hospital. Patient transfers often become a multifaceted experience as multiple transitions can occur within various settings during one hospital admission.

Ideally, the transfer of patients within the healthcare system, particularly from intensive care, should entail a safe, timely and efficient movement from one level of care or setting to another, providing seamless care and promoting the continuity of care (Naylor, 2000). However, the boundaries between intensive care and the wards have become more fluid, leading to higher acuity patients with complex demands on the wards that already have high patient-to-nurse ratios, staffing issues and nurses with varying levels of experience. As a result of boundaries becoming more fluid patient transfers can become a source of stress for ward staff and may result in a less than a seamless experience for patients and their relatives.

This thesis examines the transition of patients from intensive care to the ward environment from a ward nurse's perspective. It aims to explore the experiences of ward nurses, identify any areas of concern, highlight specific problems that occur as 
part of this transition and to address what information is pertinent to ward nurses upon patient transfer within the a large metropolitan hospital.

This thesis' research interest stems from a personal interest in what happens beyond the boundaries of Intensive Care. As an ICU nurse with experience in a number of Intensive Care units in New Zealand (NZ) and the United Kingdom (UK), my experience suggests that there are often delays in the transfer of patients from ICU to ward environment due to insufficient nursing staff on wards, transfer decisions being made without forward planning (both from a nursing and medical perspective) and delays in discharge documentation from medical staff. A lack of forward planning from a ward perspective may also be occurring in regard to bed and staffing management, complicated by an overall lack of hospital beds. In addition, inadequate warning about patient movements creates issues for bed and nursing allocation decisions and may see ward nursing staff often unprepared for patient admissions from ICU. Anecdotal reports suggest that ward staff can also be left with a high acuity patient without adequate resources; families can add to the pressure, as they are familiar with one-to-one nurse patient ratios and the change to a ward environment, whilst welcome may also provoke anxiety. Anecdotal reports from ward nursing staff in the study hospital further suggest they receive inadequate nursing data. Previous vital signs and fluid balance status data is often retained in ICU for the majority of patient transfers, as this data was getting misplaced within the hospital system. Communication, particularly during the handover appears to be an area of concern based on personal observation and feedback from the health service’s anonymous incident monitoring system, hospital incident reporting and discussions during Quality Assurance meetings. 
This introductory chapter provides an outline of the overall thesis, which includes the following chapters - setting the scene, the literature review, methodology and methods, findings, discussion and conclusion and recommendations. Chapter two provides the background to the nature of Intensive Care and an overview of the study setting and its ICU in order to set the scene. The current transfer process of patients from intensive care to the ward is also outlined.

Chapter three provides an overview of the literature, the search process undertaken and places 'transition' as a concept in relation to nursing. It appears few studies have explored in-depth the transition of patients from ICU to the ward environment from a ward nurse's perspective. There is extensive literature that examines the experiences of patients and families and the concept of transfer anxiety/relocation stress for the patient. Other literature addresses discharge planning in intensive care, factors that influence discharge planning and how ICU nurses perceive discharge planning is discussed. There is some agreement in the limited literature on the experiences of ward nurses receiving patients from ICU that ward nurses find caring for ICU patients stressful, and that patients and families have a lack of awareness and understanding of staff workload and patient allocation. Other difficulties faced by ward staff included patient-nurse relationships, knowledge and clinical skills, communication, interventions, families and general problems. This study aims to add to the knowledge about the ward nurses' experience of the transition of patients from ICU to the ward environment.

A qualitative descriptive framework is used to explore the transition of patients from ICU to the ward from a ward nurse's perspective as described in chapter four. The use of focus groups as the method of data collection is described 
their history, and their advantages and disadvantages. An overview of the research design is described, outlining the recruitment process, the focus group interview process, data analysis, ethical implications and rigour of the research.

Chapter five outlines the findings from the focus groups. Overall, ward nurses perceived the transfer process, commonly referred to as the nursing handover, to be usually very good. Five themes emerged from the focus group discussions; patients as intensive care staff say they are, time to prepare the biggest thing, documentation as a continuation of patient care, they forget what its like and families, the need to know about them. Each theme is elaborated on with quotations from the focus group discussions to support the findings.

Chapter six compares and engages the findings with the nursing literature, along with any new findings that offer additional information to the research field. Communication was a recurring element in all themes that emerged in the findings. Recommendations are discussed to facilitate the preparation of receiving patients from ICU, such as pre transfer visits. Documentation is a key area identified within the findings and strongly supported by the literature, particularly in relation to continuity of patient care and is discussed in relation to fluid balances, observation charts and transfer forms. Availability of experienced staff and safe staffing levels are a common concern in the ward context and are discussed in relation to how experience impacts on receiving patients from ICU, education of staff and a general lack of support. Families are an additional component to the transfer process and are perceived by ward nurses to be a part of nursing care, an extension of their current roles. Recommendations are discussed to support families in this transition process. 
Chapter seven concludes with an overview of all the research and what this thesis adds to nursing research. Recommendations are made that particularly focus on clinical practice issues and future nursing research. Limitations of the research are discussed in relation to sample size and applicability of the research. 


\section{Chapter 2: Background - setting the scene}

Like any health care resource intensive care is a finite resource that needs to be utilised efficiently to ensure the maximum benefit for patients most likely to benefit. This chapter defines intensive care and addresses some of the reasons why it is a finite resource, especially as faced with decreasing availability of hospital ICU beds. A general background of the study setting hospital and its ICU is given to set the scene, along with admission, discharge and triage criteria that align with the Society of Critical Care Medicine (1999) recommendations. An outline of the current transfer process to the ward is given, highlighting protocols utilised, current transfer documentation used and reasons for discharge/transfer delays.

\section{Intensive care as a finite resource}

Intensive Care is considered the highest level of patient care. The Intensive Care Clinical Advisory Group (2005) in conjunction with the Joint Faculty of Intensive Care Medicine (JFICM) defines intensive care as:

... a speciality staffed and equipped, separate and self-contained section of a hospital for the management of patients with life threatening or potentially life threatening conditions. Such conditions should be compatible with recovery and have the potential for an acceptable future quality of life. An intensive care provides special expertise and facilities for the support of vital functions and utilises the skills of medical, nursing and other staff experienced in the management of these problems. (p. 8)

(JFICM, 1997 as cited in Intensive Care Clinical Advisory Group). 
This definition encompasses a key aspect of critical care, where the aim is to treat patients with life-threatening but potentially reversible conditions; hence prioritisation should occur for those patients most likely to benefit from intensive care. Consequently a balance needs to occur between resources and the prospect of benefit to the patient.

The overall demand for intensive care resources has a significant impact on patient flow from admission to discharge throughout the intensive care journey. Intensive Care resources may include: trained medical staff, critical care nurses, respiratory therapists, mechanical ventilation, technological equipment, technicians, general personnel and most importantly, bed availability. Aspects that may influence bed availability include staffing, admission/discharge decisions, open versus closed ICU's, seasonal peaks and the additional presence of a high dependency unit (Chaboyer, Thalib, Foster, Elliott, Endacott et. al, 2006). The increased demand for intensive care resources is frequently influenced by a number of factors: an aging baby boomer population, increasing number of trauma patients, advanced technology, increased expenditure on healthcare, greater demand for major surgical interventions and a focus on treatment rather than prevention (Coombs, 2001; Dawson, 1993; Intensive Care Clinical Advisory Group, 2005; Schumaker, Hill, \& Garpestad, 2005).

Another influence on intensive care bed pressures is the universal advance in medicine and surgery. The need for admission to ICU post procedure is often complicated by pre-existing medical conditions, consequently patients are sicker on general hospital admission, and also as a direct result of complications from the surgical procedure itself (Ridley, 1998). The increase in high risk elective 
procedures, such as cardiac surgery, particularly with cardiothoracic surgeons operating on sicker patients, also impacts not only on the demand for critical care beds but also on the patients' length of stay in ICU, resulting in an overall increase in the use of resources.

The level and intensity of care in an ICU is greater than that available within the ward context or an intermediate care unit, for example, high dependency unit. Accordingly the cost of caring for a patient per day in an ICU is 3-5 times more than caring for a patient per day in a general ward (Bonvissuto, 1994). Often this factor is not recognised. In New Zealand (NZ) the costs of caring for a patient in ICU varies between \$1500-3000 per day (Havill \& Lawrence, 1999). Most costs associated with ICU care are technology and nursing labour. Nursing labour costs can be related to lower nurse-patient ratios and the specialisation of nurses within ICU. However, inappropriate usage of ICU beds is the most significant cost, for example, longer than necessary lengths of stay in ICU (Bonvissuto, 1994).

According to the Australian and New Zealand Intensive Care Society (ANZICS) the number of available intensive care beds per 100,000 population has decreased over the last few years, alongside that of general hospital bed numbers. A report from ANZICS on Intensive Care Resources and Activity (2002/2003), identified a decrease in available ICU beds and ventilator beds within NZ. These figures are represented in Tables 1 and 2 below. 
Table 1: Available Beds/100,000 between 2000/2001 and 2002/2003

\begin{tabular}{|l|l|l|l|}
\hline Region & Available beds/ & Available beds/ & Available beds/ \\
& $\mathbf{1 0 0 , 0 0 0}$ in & $\mathbf{1 0 0 , 0 0 0}$ in & $\mathbf{1 0 0 , 0 0 0}$ in \\
& $\mathbf{2 0 0 0 / 2 0 0 1}$ & $\mathbf{2 0 0 1 / 2 0 0 2}$ & $\mathbf{2 0 0 2 / 2 0 0 3}$ \\
\hline North Island & 6.0 & 5.5 & 5.4 \\
\hline South Island & 5.9 & 5.8 & 5.3 \\
\hline New Zealand & $\mathbf{6 . 0}$ & $\mathbf{5 . 7}$ & $\mathbf{5 . 3}$ \\
\hline
\end{tabular}

Table 2: Ventilator Beds/100,000 between 2000/2001 and 2002/2003

\begin{tabular}{|l|l|l|l|}
\hline Region & Ventilator beds/ & Ventilator beds/ & Ventilator beds/ \\
& $\mathbf{1 0 0 , 0 0 0}$ in & $\mathbf{1 0 0 , 0 0 0}$ in & $\mathbf{1 0 0 , 0 0 0}$ in \\
& $\mathbf{2 0 0 0 / 2 0 0 1}$ & $\mathbf{2 0 0 1 / 2 0 0 2}$ & $\mathbf{2 0 0 2 / 2 0 0 3}$ \\
\hline North Island & 4.4 & 4.3 & 3.9 \\
\hline South Island & 4.4 & 4.2 & 3.2 \\
\hline New Zealand & $\mathbf{4 . 4}$ & $\mathbf{4 . 4}$ & 3.7 \\
\hline
\end{tabular}

(Higlett, Bishop, Hart, \& Hicks, 2005, p.71. Reprinted with permission).

The increasing population and decreasing number of hospital beds has compounded to mean that the number of available ICU beds has also decreased (Higlett et al., 2005). This overall trend adds to the constraints in resource allocation while working within such a dynamic environment such as ICU, as it is very difficult to plan in advance how sickness will be managed.

A shortage of ICU beds is an everyday occurrence within most acute hospital settings and bed allocation is considered one of the most difficult and stressful aspects of an intensivists' work. Giannini and Consonni (2006) study addressed 
'Physicians' perceptions and attitudes regarding inappropriate admission and resource allocation in the intensive care setting' and acknowledged four major findings. Firstly, inappropriate admissions to ICU were seen as a common event, though this was credited mainly due to the actual difficulties in assessing the appropriateness of the admission, such as limited time or a multifaceted clinical picture. Secondly, physicians recognized that their decisions were not solely based on medical reasoning but often influenced by external factors, such as pressure from superiors or referring doctors, from families who want everything done, or the threat of legal action. Thirdly, economic factors such as pressure to utilise ICU beds more effectively by unit and hospital managers as well as colleagues. In the United States of America (USA) it is suggested that financial incentives and disincentives have been used to manipulate intensivists' decisions in ICU. Fourthly, decisions such as withdrawal of treatment could also be influenced by non-clinical considerations. Such decisions are deemed acceptable if the patient has a reasonably low chance of survival, particularly when a referral for a more urgent admission is received, yet an ICU bed is not available. Decisions to withdraw treatment are made in consultation with the patient, families, and medical team and respect the principle of proportionality of treatment. Giannini and Consonni (2006) empathise that when ICU resource rationing is essential these negotiations should be conducted openly and discussed thoroughly.

Despite the high costs of technology and staffing, the most significant contributor to ICU costs is the inappropriate use of ICU beds (Bonvissuto, 1994). Yet, like many therapies, critical care is considered as a standard of practice and not recognised as a scarce resource. Dawson (1993) argues that like any other scare resource, it should meet the minimum criteria used to regulate other high cost 
resources, such as transplant programmes, before being utilised. Further, these criteria include that: conventional therapy is inadequate; the pathology should be reversible; the resource must be available; the resource must be effective with regard to the pathology; and that no ethical, moral or legal burden exists. Some patients and families presume they have a right to ICU care no matter what the circumstances, regardless of whether the patient may benefit from treatment or that another person's needs may be greater. It is acknowledged that this is more likely to be an American perception due to their unique concept of service and having to pay for healthcare services through health insurance.

\section{Admission/discharge/triage criteria}

Clear documented admission, discharge and triage criteria have been recommended as a strategy to improve the use of intensive care resources within the literature (Dawson, 1993; Society of Critical Care Medicine, 1999) and hence patient flow in relation to intensive care. Typically ICU's should have written admission and discharge policies based on physiological conditions and resource requirements. Ideally critical care should be limited to those who need it; therefore admission criteria should select patients who are most like to benefit from intensive care.

The Society of Critical Care Medicine (1999) outlined a prioritisation model system that defines those that will benefit most from ICU (priority one) to those who will not benefit at all (priority four). A priority one is defined as: “---critically ill, unstable patients in need of intensive treatment and monitoring that cannot be provided outside of the ICU” (p. 4). 
These intensive treatments might include ventilatory support or vasoactive drug infusions. These patients have no limits put on the amount of therapy they receive. Examples include: acute respiratory failure; treatment of shock; haemodynamically unstable patients; post-operative patients; and those requiring airway protection. Other specialised examples include burns, dialysis, overdoses and high-risk obstetrics/gynaecological patients. Dawson (1993) is more precise in outlining criteria for admission to critical care, although uses similar specific physiological conditions as mentioned above. All these types of conditions fulfil the broader context of a priority one patient as outlined by the Society of Critical Medicine (1999).

Discharge criteria from intensive care are not as simple as the patient requiring less care. Ongoing evaluation of a patients' progress within ICU occurs to determine whether they still require intensive care support. Criteria for discharge include: a patient's physiological condition has stabilised and no longer requires ICU monitoring and support; or the other end of the scale, when a patient's physiological condition has deteriorated and active treatment is no longer appropriate (Society of Critical Care Medicine, 1999). Again, Dawson (1993) is more detailed in outlining discharge criteria: specific examples include brain death when donation is not planned; patients undergoing withdrawal of support; patient is breathing spontaneously (stable airway, intact cough, etc); no longer receiving vasoactive drugs; and the patient who is haemodynamically stable no longer requiring continual monitoring. In contrast, Heidegger, Treggiari and Romand (2005) emphasise that written discharge criteria in ICU's are of limited value without supporting bedside clinical examination of the patient by an experienced clinician. 
Other factors such as patient safety and communication with the receiving ward must be taken into account. Both the discharging and receiving unit medical and nursing staff should be satisfied of the discharge prior to patient transfer. Often medical staff deem a patient acceptable for discharge but have not taken into account the increased nursing care the patient may require on the ward, due to the patient's level of acuity. Consequently, communication between the discharging and receiving unit is crucial to ensure patient safety. Ideally, the discharge criteria from intensive care should correspond with the admitting criteria at the next level of care, for example, high dependency unit or ward (Society of Critical Care Medicine, 1999).

At times ICU's have to go into 'triage mode', where prioritisation of patient care occurs based on the ability to benefit. These 'triage' situations might occur when the ICU is operating at full capacity; there is a major disaster, such as an earthquake; a major accident has occurred where multiple admissions are expected; or in the case of a significant fire, where evacuation procedures are implemented. Triage situations involve the careful review of potential admissions, the acceleration of discharges of both the patient who can be safely transferred and those patients who have not responded to therapy (Strosberg, 1993). Therefore these decisions must be made unequivocally and without bias. These unplanned transfer situations potentially cause added stress for ward staff and patients alike. The Society of Critical Care Medicine (1999) emphasises that if admissions to critical care are meticulously screened for benefit and discharges are constantly evaluated, then the need for triaging is reduced. 
The nature of ICU as a finite resource requires that prioritisation needs to occur for those patients most likely to benefit from ICU; hence a balance needs to occur between allocation of resources and the potential benefit to the patient. This demand for ICU resources has a momentous impact on patient flow from admission to discharge within ICU, where the greatest resource is bed availability, an everyday occurrence within the acute hospital setting. Admission, discharge and triage criteria have been recommended to improve the use of ICU resources.

\section{The study setting}

The study setting is a large metropolitan hospital that is a 600-bed tertiary referral and trauma hospital covering the midland region of New Zealand, serving a population of 800,000 people. The ICU within this hospital provides medical/nursing teams for interhospital transfers (Flight Services). The ICU has 15 beds and admits over 1200 patients per year. The ICU is a mixed unit with paediatrics and adult admissions. Types of patients admitted include elective cardiac surgery, trauma, medical, surgical, and the recent introduction of neurosurgical patients.

The ICU medical team primarily manages patients within the hospital's ICU, though specialists' teams' opinions are valued and sought. This concept is known as a 'closed unit', whereby only the ICU consultant or registrar has the authority to admit and treat ICU patients (Strosberg, 1993). This describes the degree of centralisation of management functions that occur regarding admission, discharge and triage decisions. It is the ICU's policy that no patient is admitted without the knowledge and consent of the duty ICU consultant. In contrast, an open unit is where 
specialists can admit without prior approval and the specialists become the primary provider instead of the intensivists.

\section{Study hospital's ICU admission/discharge/triage criteria}

The study hospital's ICU has written admission, discharge and triage criteria as recommended by the Society of Critical Care Medicine (1999), as well as policies that directly relate to patient refusal and withdrawal of therapy. Intensive Care's admission policy coincides with the Society of Critical Care Medicine's guidelines (1999), whereby patients are likely to benefit in some way as a result of an ICU admission - in particular patients with actual or potential organ failure, which is potentially reversible with the provision of intensive support measures. In contrast, elective admissions, such as paediatric or cardiac surgery, are booked but have to be confirmed prior or on the day of surgery for bed and staffing availability. Often, due to a lack of bed availability or nursing shortages, elective surgical cases can be cancelled or referrals refused.

The ICU has based their triage criteria on the Society of Critical Care Medicine (1999) Prioritisation Model. This model identifies those that will benefit most from ICU (priority one) to those that will not benefit at all (priority four). A priority one patient includes critically ill patients in need of monitoring and treatment that is not obtainable outside the ICU, whereas a priority four patient is one who is generally not appropriate for ICU admission as their disease is terminal or irreversible with imminent death (Society of Critical Care Medicine, 1999). This category would also include patients not expected to benefit from ICU based on the low risk of the intervention that could be administered elsewhere, such as people 
who are conscious after taking a drug overdose, have haemodynamically stable diabetic ketoacidosis or mild congestive heart failure.

Within ICU discharge policy, all discharges must be approved by the duty ICU consultant. All patients' care is transferred to the parent team via the ICU registrar to the specialist team's registrar. Ideally, all other teams involved should be advised, such as physiotherapists, pharmacists, dieticians or the pain team. Registrars must discuss the plan of care for the immediate discharge period with the accepting team and clearly document this in the medical notes including limitations of treatment where appropriate, non-return orders and a clear medical management plan for the next 24 hours. It is recognised that nurses will not send patients to the ward without first checking with the registrar on duty.

\section{Current discharge/transfer process}

The policies that underpin the transfer process within the ICU are the Admissions/Transfers Nursing Policy, the General ICU Guidelines and the Medical Protocol for Ward Transfer of Cardiac Surgery Patients. The nursing policy outlines the process for transferring patients out of ICU and encompasses: ringing the ward charge nurse/coordinator to check bed availability; arranging a suitable time for transfer; organising an orderly to collect the bed from the ward; notifying relatives of pending transfer; completing relevant nursing transfer form; nursing management (duty manager) being informed of patient transfer out; and the ICU admission book being filled out. This policy acts as a guideline only for nursing staff. 
Often ICU is dependent on the wards discharging patients in order to receive ICU patients; hence a delay in the transfer process occurs. This could be perceived as a benefit to ICU nurses as it allows them more time to organise a thorough patient transfer, with a flow-on effect for ward nurses in receiving a smooth patient transfer. Occasionally the hospital is in 'bed block', where patients literally cannot be transferred out of ICU and the hospital duty manager ultimately is responsible for liasing with wards; this often results in ICU retaining patients longer than necessary.

Currently within the ICU there are three different transfer forms that exist as part of patient transfer documentation to be completed, each catering to the individual needs of each patient population: a general patient transfer form; a paediatric form; and a cardiac surgery form. Examples of the headings in a general patient transfer form are given in Box 1.

\section{Box 1: Headings in General Transfer Form: \\ - Reason for ICU admission \\ - Medical history \\ - Summary of treatment \\ - Allergies \\ - Present condition (basic systems approach) \\ - Current medications \\ - Invasive lines \\ - IV fluids/drug infusions \\ - Analgesia \\ - Wounds/Drains/Tracheostomy in-situ \\ - $\quad$ Transfer checklist (medical/nursing documentation + patient property) \\ - Psychological needs}

Presently, it appears the cardiac surgery transfer form is not being completed as nurses are documenting patient transfer information in the medical notes. This process seems to be informal in nature as no formal cardiac procedure exists; this is 
currently under review. It should be noted at this point that both the cardiothoracic ward and the high dependency unit are the only two wards that receive all ICU documentation, in particular the ICU 24-hour chart, which details patient's observations, ventilation and fluid balance status.

Despite the policies that are in place, the transfer process can be ad hoc in nature often due to delayed decisions to discharge patients from ICU, where frequently these decisions are made on the ICU ward round on the day. This can impede the transfer process where ICU nurses are unable to formally plan a thorough patient transfer to the ward. Watts, Gardner and Pierson (2005) suggest delays in the transfer process can be hindered by a lack of communication between nursing staff and medical staff, where nurses have little control over discharge planning as the ultimate decision to discharge a patient is a medical one.

Delayed discharges from intensive care impact significantly on the effectiveness and efficiency of ICU services, due to the increasing demand for ICU beds. Williams' and Leslie’s (2004) cross sectional study examined the occurrence and reasons for delayed discharges in an adult ICU. The most common reason being a lack of available ward beds, a phenomenon in most hospital settings. This may be related to hospital bed management practices, unpredictable emergency admissions and the ward-discharge process itself. Williams and Leslie suggest that the only two factors that can be controlled by the hospital in order to reduce discharge delays from intensive care are bed management and discharge processes. Other discharge delay factors include: medical reasons (differing views of intensivists), severity of illness on admission, refusal from the accepting ward due to acuity of the patient or a lack of nursing resources. Delayed discharges from ICU have cost implications such as 
increased nursing hours (consequently increased nursing costs), increased length of ICU stay and the cost of caring for a patient in ICU, which can vary between \$NZ 1500-3000 per day (Chaboyer et al., 2006b; Havill \& Lawrence, 1999). Delayed discharges have a significant effect on resources within intensive care, especially when there is pressure to accept a new ICU admission.

\section{Conclusion}

In order to understand the transition of patients from ICU to the ward it is important to understand the nature of ICU and the confines it works within, which ultimately impacts on patient flow from ICU to the ward environment and to a degree on the ward nurses that receive these critically ill patients. The acuteness of ICU and the demand for its services, often still results in an ad hoc transfer process, having a flow on effect for ward nurses when receiving these critically ill patients. This occurs despite being supported by admission, discharge and triage criteria as a means of managing patient flow, alongside protocols and guidelines to assist nursing and medical staff in the smooth transfer of patients to the ward.

To explore the transition of patients from ICU to the ward from a ward nurse's perspective a literature review was carried out, as discussed further in the following chapter. Very little research exists specifically on the experiences of ward nurses receiving patients from ICU. Supporting literature around the transfer of patients to the ward looks at the experiences of patients and families and the concept of discharge planning, how ICU nurses perceive it and factors that impede discharge planning. 


\section{Chapter 3: Literature Review}

Exploration of the transition of patients from ICU to the ward from a ward nurses' perspective has received little attention in the nursing literature, in particular the experience of ward nurses receiving these critically ill patients. In order to explore this phenomenon further a literature search was carried out using the search strategy set out below.

\section{Search strategy}

The search strategy adopted during the literature review included terms such as: 'INTENSIVE CARE' or 'CRITICAL CARE' (which takes into account the English and American terminology), 'PATIENT TRANSFER', 'TRANSFER', 'TRANSITION', 'TRANSITIONAL CARE', CONTINUITY OF CARE', 'DISCHARGE', 'PATIENT DISCHARGE' and 'DISCHARGE PLANNING'.

These keywords were identified based on their commonly used clinical terms, a technique recommended by Brown (1999). A search of Cinahl, Proquest, and Medline databases was carried out using the above key words. Other search techniques include Boolean operators, truncation searching and reference lists (Brown). Boolean operators, such as 'and', were used to combine multiple search terms as a way of narrowing the search and identifying articles with common multiple keywords. Limits were set to refine the search such as adult, English written articles and those published within the last 15 years. Reference lists from relevant articles were also checked as a method of finding similar articles or to source a primary reference. Internet searches using 'Google Scholar' and highly recognised 
Intensive Care Nursing Journals (for example, Intensive \& Critical Care Nursing, Critical care Nurse and Critical Care Nurse Quarterly) were also carried out, alongside hand searches of journals.

Themes within the literature include transitional care, patient and families' experiences of transfer from ICU, discharge planning and the experiences of ward nurses receiving patients from ICU. The concept of transitional care is examined and how it relates to the nursing discipline and its significance in ICU. Extensive literature has been written about the experiences of patients' and families' transferring from ICU, especially that of transfer anxiety/relocation stress (Coyle, 2001; Leith, 1998; McKinney \& Melby, 2002; Odell, 2000; Saarmann, 1993; Strahan \& Brown, 2005). It is recognised within the literature that patients' can experience both adverse physical and psychological effects after being transferred from ICU. Discharge/transfer planning is acknowledged within the literature as a process to promote continuity of patient care, a process that is perceived as a low priority for ICU nurses and which ward nurses appear not to be involved in. Various reasons are discussed within the literature for a lack of discharge planning, the most significant being the dynamic nature of the ICU patient (Ball, 2005; Chaboyer, Foster, Kendall, \& James, 2002; Schlemmer, 1989; Watts, Pierson, \& Gardner, 2005; Whittaker \& Ball, 2000). These patients ongoing care is then provided in the ward environment and impacts on ward nurses, particularly as these patients are highly dependent with multiple complex needs. From the literature search it appears few studies have explored in depth the transition of patients from ICU to the ward environment from a ward nursing perspective. The literature that is available is discussed in relation to the difficulties faced by ward nurses such as stress, knowledge and skills, communication and families. Whether the literature describes the movement of 
patients from ICU to the ward as discharge, transfer or transition, the impact this has on patients and their families, nurses are still the primary health professionals involved in these periods of change.

\section{Transition as a concept}

Transition as a concept is central to the nursing discipline as a whole. Nurses often are the primary health professionals involved in encounters with patients and their families that relate to transitional periods of instability precipitated by situational, developmental or health-related illness changes (Meleis, Sawyer, Im, Messias, Schumacher, 2000; Schumacher \& Meleis, 1994;). Transition is the consequence of change, which ultimately results in changes in a person's life. Schumacher and Meleis and Meleis, et.al suggest that nurses need to consider the patterns of all-important transitions in a patients'/families' life rather than concentrating on one specific type of transition. As patients may be transferred more than once during their hospital admission, each transition symbolises unique challenges for patients, their families and the nurses involved in their care.

Literature around the concept of transition is highlighted in a number of settings: transitional care models, research with elderly and research in neonatal care. Transitional care settings evolved in the 1980's in the USA as a more cost effective way of caring for patients in need of long-term care. Transitional care models comprise a variety of intermediate services, including sub acute care, skilled nursing facilities, and rehabilitative care services (Brzozowski, 1998; Griffin, 1998; Jones \& Foster, 1997). These transitional care facilities are designed for patients with complex medical and surgical problems, complex wounds or long term weaning 
from mechanical ventilation. Nursing staff who manage patient care also coordinate the multidisciplinary team. The focus of transitional care facilities is a smooth transition process for individuals from the acute care environment to home.

Ultimately, transitional care ensures the safe and timely transfer of patients from one level of care to another, for example, acute to sub acute or from one type of setting to another, for example, hospital to home (Naylor, 2000). Naylor's research developed from testing and refining a transitional care model with hospitalised elders. This model focused on improving post discharge outcomes for older adults admitted to hospital for an acute exacerbation of chronic cardiovascular illness. This work involved testing the effects of comprehensive discharge planning for hospitalised elders with variations on intervention from discharge planning with telephone follow-up or discharge planning with home follow-up. A further study by Bixby, Konick-McMahon and Mckenna (2000) utilised the transitional care model for elderly patients with heart failure in order to decrease the length of hospital stay. The same comprehensive discharge planning was used with home follow-up for a three-month period. These examples of transitional care, delivered by Advanced Practice Nurses (APN), provide for the unique needs of the elderly and aim to keep these patients from returning to hospital.

Work around transitional care for neonatal patients has focused on providing transitional care within hospital settings and post discharge hospital support. Such a programme in Calgary called the Neonatal Transitional Care Program assists homeward bound very low birth weight infants and their families, providing in-home and telephone support for four months after the infants are discharged (Lasby, Newton, \& Von Platen, 2004; Rudolph Durrie, 2002). The result has been a decrease 
in demand for healthcare resources, for example, decreased emergency department visits, and an increase in the effectiveness of breast-feeding, increased customer satisfaction and overall enhanced maternal confidence.

The increased demand on resources and pressure for neonatal intensive care cots is similar to that of adult intensive care beds, creating a need for transitional care units within the hospital context for higher risk infants who do not require intensive care nursing (Bromley, 2000). Transitional care units are common within the US, Canada and UK. Such units have shown to be beneficial to compromised neonates and their families, ensuring good outcomes for neonates, promoting family centred care and better utilisation of resources (Bromley, 2000; Duddridge, 2001).

Transitional care within the context of ICU relates to "care provided before, during and after the transfer of an ICU patient to another care unit that aims to ensure minimal disruption and optimal continuity of care for the patient," as defined by Chaboyer, James and Kendall (2005, p. 16). This definition incorporates Naylor's (2000) theory on transitional care in relation to the movement of patients from one level of care to another. Chaboyer et al. recognise that multiple transitions occur for ICU patients; the two most significant are the transition to an intermediate care and then to home. Four major current strategies for ICU transitional care include: changes in ICU discharge planning practices; the use of ICU liaison or discharge nurses; step down units (for example, high dependency units); and outpatient followup clinics. Discharge planning is aimed at improving patients' preparation for discharge from ICU and further developing ICU discharge planning practices; extended nursing roles and step down units are largely targeted as the transition from 
ICU to the immediate care unit; and outpatient clinics are more focused on the transition from hospital to community.

\section{Transfer from intensive care}

Transfer from intensive care to the ward is a positive indication of progress towards better health, yet it creates negative feelings such as fear, anxiety and may cause stress (McKinney \& Melby, 2002 Saarmann, 1993;). This concept of transfer anxiety transpires when patients are moved from a familiar environment, where they feel safe and secure, to that of an unfamiliar environment (Coyle, 2001; Leith, 1998; McKinney \& Melby, 2002; Saarmann, 1993) . Other terminology used includes transfer stress, translocation syndrome and relocation stress. Carpenito (2002) defines relocation stress as "a state in which an individual experiences physiologic and/or psychological disturbances as a result of transfer from one environment to another" (p. 722). Consequently, the transition from intensive care to the ward in itself can be distressing not only for patients, but also their families and/or significant

others. As they have spent significant time in the intensive care, it becomes an environment they identify with, where they feel safe and secure, and provides a sense of familiarity to them.

\section{Patients and families experiences}

The transfer process can create significant stress and anxiety for patients and families, especially as these decisions can be made with minimal consultation and little or no preparation. Families and patients progress from situations of being continually exposed to health professionals and one-to-one nurse patient ratios, to 
one of limited contact on the ward and where nurse to patient ratios are significantly higher. Patients and families expect care and monitoring to continue as before, as patients continue to perceive themselves as critically ill (Coyle, 2001; Leith, 1998). Whittaker and Ball (2000) suggest that a poorly coordinated transition process may exacerbate relocation stress, resulting in physical and psychological issues that can lead to a delay in recovery and potential re-admission to ICU.

Fright can also occur, firstly when coming to terms with their illness and secondly on transfer to the ward, as patients and families do not know what to expect in a different environment where routines, treatment and monitoring can be different (Coyle, 2001; Leith, 1998; McKinney \& Melby, 2002; Saarmann, 1993). Fright and anxiety can also be exacerbated by the sudden decrease in monitoring of the patient prior to transfer and a lack of control over the environment. Transfer anxiety remains a significant problem experienced by many patients who have been in intensive care.

Patients can experience both physical and psychological disturbances, short and long-term effects post transfer from ICU. The long-term effects however are beyond the scope of this discussion. Strahan and Brown (2005) addressed the experiences of patients following transfer from intensive care and three key themes emerged: physical responses; psychological responses; and provision of care. Patients' experiences of moving from ICU to the ward ranged from positive, for example, “---progression along the continuum from independence to dependence--”, to negative and some patients had no recollection at all (Strahan \& Brown, p. 167). Others experienced a lack of emotional preparation and a lack of information prior to being transferred. 
Odell (2000) also explored patient thoughts and feelings about their transfer from intensive care to the ward, using a phenomenological approach. Three themes emerged from the data: detachment, acceptance and mixed feelings. Detachment was associated with feelings of indifference and not remembering, which when probed further led to ambivalent feelings (negative followed by positive), suggesting that patients have vague recollections of ICU or that no recollection may be used as a coping mechanism (Odell). Patients expressed a certain level of acceptance, having little control, with a belief to comply with hospital staff and “---accept their destiny in the hospital process” (Odell, p. 326). This study emphasised that patients' feelings can be mixed, positive and negative, though predominantly positive in relation to getting better. Odell acknowledges that it is important that patients need constant information updating, a role in which nurses can have a considerable impact.

Nurses can play a significant role through appropriate nursing interventions aimed at reducing transfer anxiety. Leith (1998) conducted informal interviews and found that patients and families benefited from visits from ward staff prior to transfer and visits by ICU staff post transfer as a means of decreasing transfer anxiety. Saarmann (1993) and McKinney and Melby (2002) also acknowledge the significance of pre-transfer visits from the nurse who will be caring for the patient on the ward. However, this may not always be practical due to time and resource constraints within the ward environment. Roles such as Clinical Nurse Specialist (CNS) or ICU Liaison Nurse have been advocated to follow-up patients after transfer to the ward as a means of ensuring continuity of care (Green \& Edmonds, 2004; Hall-Smith, Ball, \& Coakley, 1997; McKinney \& Melby). The Liaison Nurse role focuses on pre and post transfer, whist the CNS appears to focus on post transfer. Both roles appear to have components of reducing relocation stress/transfer anxiety 
as they assess the patients/families adjustment to transfer from ICU to the ward by clarifying events, answering questions, addressing specific concerns and promoting realistic expectations about recovering from critical illness (Green \& Edmonds; HallSmith et al.). Hall-Smith, Ball and Coakley eloquently summarise the role of the CNS as:

---to act as a link between the ICU and the wards in an attempt to ensure a smooth and safe transition from the ICU, to address problem areas and to provide support and advice to ward staff, patients and their families (p. 247).

Interestingly, Russell (1999) looked at the factors that contribute to readmissions to ICU from the general ward and one of the key factors was inadequate follow-up care on the general wards. Evidence of this included time constraints, poor communication, difficulties caused by the lack of resources in the wards, a lack of knowledge and busy staff (Russell). Russell argues that the provision of specific follow-up services to patients after their transfer from ICU could prevent costly readmissions to ICU and recommends the role of the follow-up nurse as a means of improving continuity of care for patients’ transferred from ICU.

Pre-transfer teaching provides a means of sharing information about the transfer process to create awareness for patient and families of what to expect. This information should include changes in the care the patient will receive and the environment (Saarmann, 1993). Mitchell and Courtney (2005 a, b, c) conducted three studies as part of a larger project. They first developed, implemented and evaluated a transfer brochure for family members of patients' in ICU to improve transfer to the general ward (Mitchell and Courtney, 2005a). They next evaluated family members’ (Mitchell \& Courtney, 2005b) and then ICU nurses (Mitchell \& Courtney, 2005c) 
perspective of the written brochure designed to improve the transfer of ICU patients to the ward. The studies showed that ICU nurses recognized communication about patient transfer was often disregarded and noted the brochure helped them support and direct their discussion about patient transfer with the family. Families, on the other hand, acknowledged considerably more satisfaction with the information received, had better understanding of the information and were more informed of patient's transfer plans.

A similar study by Paul, Hendry and Cabreilli (2003) also looked at the development of an information booklet for patients and relatives preparing them for transfer from ICU. Similar results regarding patients and relatives satisfaction with information arose and demonstrated improved communication with the wards. Most importantly, the study acknowledged the need for greater staff education in regard to patients and families needs when transferring to the ward. Such booklets have also been utilised in the paediatric arena. The transfer issues for paediatric patients and more so their families are the same as for adults - i.e. transfer to an unfamiliar environment with different routines, lack of preparation, leaving familiar staff and reliance on monitoring equipment (Van Waning, Kleiber, \& Freyenberger, 2005). These types of booklets can be useful in preparation and planning for transfer of the patient to the ward in order to decrease transfer anxiety and enhance communication.

Timing of the patient transfer is also significant. Patient transfers that occur un-expectedly or at night can provoke anxiety and may be traumatic both physically and psychologically for patients. Night transfers in particular can make it difficult for patients to cope with adapting to their new environment and increase confusion in patients (Leith, 1998; McKinney \& Melby, 2002). Potential consequences of 
transferring patients at night may include an unexpected re-admission to ICU and an increased risk of mortality due to premature transfer/discharge (Duke, Green, \& Briedis, 2004). Often premature discharges at night are associated with a new admission to ICU in order to create bed availability. Goldfrad and Rowan (2000) suggest the main reason why night transfers do worse than daytime transfers is that they are more likely to be premature in view of the intensivists involved. Factors that may impact on patient outcomes for night discharges relate to nursing night shift patterns on general wards where decreased staffing levels occur, lower nurse-patient ratios, along with less medical and senior nursing support. Other factors may include inadequate time for patient handover, patient assessment and observations (Duke et al., 2004). Potentially all of these factors may result in poorer quality and quantity of care available at night both during transfer and at the receiving ward.

\section{Discharge/transfer from intensive care}

Various literature discusses the concept of discharge/transfer planning as a means to ease the transition of patients from intensive care to the ward (Chaboyer, James, \& Kendall, 2005; Coyle, 2001; Leith, 1998; Saarmann, 1993; Schlemmer, 1989). The concept of 'transfer' or 'transition' does not appear to be widely used within the literature; accordingly the term 'discharge' has been used as a substitute within this section. Although, I consider the term 'transition' or 'transfer' more appropriate in the intensive care environment, as the term 'discharge' commonly relates to the discharge from hospital to home, as reflected in the nursing literature. Mosby’s nursing dictionary (Glanze, 1990) defines discharge planning as “ $a$ schedule of events often planned by a multidisciplinary team leading to the return of a patient from hospital confinement to a normal life at home" (p. 377). Anderson and 
Helms (1994) provide a similar definition, whereby discharge planning is “--- the process of coordinating the delivery of health care services beyond the hospital services” (p. 69). In comparison, Schlemmer (1989) defines discharge planning more as a transition according to the American Nurses' Association (1975) “the part of the continuity process which is designed to prepare the patient for the next phase of care and to assist in making any necessary arrangements for that phase of care ---“ (p. 88B). McGinley, Baus, Gyza et al. (1996) recognise that 'discharge' does not always specifically relate to going home, instead acknowledging it as an “--- ongoing process that facilitates the discharge of the patient to the appropriate level of care" (p. 55). The dilemma for nurses in how to perceive discharge planning is therefore apparent, due to its multifaceted definitions and ambiguity as to where discharge planning actually starts. Despite the discrepancy between the literature definitions, the ultimate goal should be to ensure continuity of patient care.

\section{Discharge planning from intensive care}

Traditionally, nurses at the bedside have focused on discharge planning within the ward environment, though nurses within intensive care appear to decline a responsibility in this process. Theoretically, intensive care nurses should have as much of a significant role in discharge planning as any other, having 24-hour bedside access to patients, a breadth of nursing knowledge and skills, experience in dealing with patients and their families and an understanding of communication dynamics. Consequently, ICU nurses are extremely suited to play a major role in discharge planning. Carr (1988) stipulates that with all these virtues all that is required to instigate discharge planning is the recognition of its importance and the knowledge of how to proceed. 
The concept of discharge planning in itself appears to be a low priority in intensive care (Chaboyer et al., 2002; Schlemmer, 1989; Watts et al., 2005). One of the main reasons for inadequate discharge planning is the dynamic nature of the intensive care environment. The significant demand for ICU beds means that discharges often occur suddenly, with little warning, resulting in inadequately coordinated discharges (Daffurn, Bishop, Hillman, \& Bauman, 1994). Various reasons are addressed within the literature for a lack of discharge planning in intensive care, such as inadequate staffing; the dynamic nature of ICU patients; increased paperwork; increased nursing workloads; higher nurse-to-patient ratios; high patient acuities; a lack of time; and a lack of understanding (Chaboyer, Foster, Kendall, \& James, 2004; Leith, 1998; Schlemmer, 1989; Watts, Gardner, \& Pierson, 2005) .

Patients' conditions and/or acuity level was a considered a key factor by ICU nurses in a study by Chaboyer, Foster, Kendall and James (2002), as it may limit the value of discharge planning. Discharge planning is influenced by the nature of uncertainty that is related to intensive care patients' outcomes. The immediate requirements of the patient during their initial stages of admission takes priority over discharge planning, alongside the uncertainty of the unknown, making discharge planning difficult to initiate and implement until the patient becomes more stable and is ready to be transferred to the ward. Unfortunately, patients' progress can be quite unpredictable; initially they may be ready to progress to the ward and then deteriorate over the next 12-24 hours. This dynamic nature of intensive care patients was identified in earlier work done by Schlemmer (1989), who acknowledged it as one of the reasons discharge planning was not implemented in ICU's. 
Discrepancy exists among ICU nurses as to when the discharge planning process should begin. Schlemmer (1989) comments that ICU nurses consider that discharge planning is not a priority and that this process should occur after a patient is discharged from ICU. Interestingly, Chaboyer et al., (2002) found that ICU nurses were split 50/50 as to whether they thought it should occur before or after discharge from ICU. Chaboyer et al., highlights that ICU nurses feel uncertainty about the discharge planning, stating “----they lacked knowledge in the area of discharge planning despite their perception that doctors gave them sufficient direction” (p. 94).

Discharge planning should be considered a transferable skill, having been learnt in the ward environment as new graduates. However, the ICU environment does require different interventions related to discharge planning, for example, decreased monitoring, removal of invasive monitoring, as Chaboyer et al. (2002) acknowledges, but in addition the author noted that ICU nurses felt ill-equipped. Consequently, the need for ongoing education and support cannot be over looked.

Nurses working within intensive care find it difficult to relate to discharge planning as a whole, as the focus within the intensive care environment is often related to saving lives, getting the patient safely to the ward and creating bed availability (Chaboyer et al., 2002; Watts et al., 2005). It can be perceived that discharge planning within intensive care is part of a bigger process, thus why intensive care nurses are uncertain as to how to define discharge planning - i.e. discharge from intensive care to the ward or discharge from hospital. Watts, Pierson and Gardner’s (2005) study identified that ICU nurses’ perceived discharge planning more as involving a 'smooth transition' of the patient from intensive care to the ward. The concept of transition emphasises the transfer of the patient from intensive 
care to the next level of care, whether that be a high dependency, a ward or another hospital facility, as opposed to discharge from the hospital. This reinforces my initial statement in this chapter regarding the use of the term 'transition' over the word 'discharge’.

\section{Factors that enhance or impede discharge planning}

Communication plays a major role in either impeding or enhancing the discharge process within intensive care. Watts et al. (2005) study recognized that written and verbal communication is significant, in particular verbal communication between intensive care nurses, between intensive care nurses and medical staff and lastly communication between intensive care nurses and ward nurses. Watts et al. suggests that the effectiveness of communication between nursing staff regarding the discharge plan is directly related to the commitment of the individual nurse, highlighting the need for improved communication processes. Watts et al. reiterates Chayboyer et al. (2002) and suggests that intensive care nurses' knowledge of discharge planning can be improved.

Delays in the discharge process can be hindered by a lack of communication. This can occur in a number of ways such as between senior nurses (co-ordinators) and bedside nurses, where the bedside nurse can be excluded from the discharge discussions. As well as between nursing staff and medical staff, where nurses have little control over discharge planning as the ultimate decision to discharge a patient is a medical one (Watts et al., 2005). Bedside nurses could argue that these constraints reinforce the perception that discharge planning in intensive care is not a priority. Yet this denial to take responsibility ultimately affects continuity of care, considering 
the bedside nurse is directly involved with patient care and therefore in a better position to understand the needs of the patient.

\section{Discharge and continuity of care}

The purpose of discharge planning is to ensure continuity of care (Schlemmer, 1989; Whittaker \& Ball, 2000) in order to enable the optimal conditions for recovery. Continuity of care is consequently related to the provision of information about the patient's condition in order for the receiving ward/department to appropriately care for that patient. Intensive care nurses therefore have a responsibility to provide appropriate continuity of care by preparing patients for transfer and involving them in the transfer process in order to reduce transfer anxiety for patient and families (Leith, 1998; Watts et al., 2005). The benefits of discharge planning include: improved patient and families outcomes; increased satisfaction; continuity of care; decreased length of hospital stay; prevention of readmissions; and a successful transition (Chaboyer et al., 2004).

Recommendations to facilitate discharge planning as previously mentioned include: daytime transfers; introductions to ward staff; family involvement in discharge planning; pre transfer teaching; post transfer visits by an intensive care nurse; decreased level of monitoring/technology prior to transfer; information booklets; and collaboration with other multidisciplinary health professionals (Chaboyer et al., 2005; Coyle, 2001; Jones \& O'Donnell, 1994; Leith, 1998; Saarmann, 1993; Whittaker \& Ball, 2000). 
The main reason for inadequate discharge planning is the dynamic nature of the ICU environment. The significant demand for ICU beds often results in discharges occurring suddenly resulting in inadequate coordinated discharges. Communication therefore plays an important role in either impeding or enhancing the discharge process in ICU, particularly verbal communication that occurs at various levels and between wards, where nurses need to take responsibility for this along with ICU nurses improving their knowledge of discharge planning to ensure continuity of care. Consequently, it is recognised that nurses play an essential role in the discharge/transition process as a means to ensure continuity of patient care and decrease transfer anxiety in patients and families alike.

\section{Transfer from intensive care: The ward nurses' experience}

This research explores the transition of patients from intensive care to the ward environment from a ward nurse's perspective. Little nursing literature has explored the phenomena of ward nurses receiving patients from ICU. Whittaker and Ball (2000) and Haines (2001) are the prominent authors in this area looking at the experiences and difficulties faced by ward nurses when receiving and caring for these patients from ICU. Hence this thesis builds on the work by these authors and further explores the nature of receiving patients from ICU from a ward nurses perspective in order to understand the issues faced by ward nurses.

Patients transferred by ICU to the ward are often highly dependent patients with multiple complex needs, both physically and psychologically. These patients ongoing care is provided in the ward environment and ultimately impacts on ward nurses, an area that is under-researched. Difficulties faced by ward nursing staff can 
be related to stress/emotions; patient-nurse relationships; knowledge and skills; communication; interventions; families; and general problems (Griffiths \& Jones, 2002; Haines, 2001; Hall-Smith et al., 1997; Whittaker \& Ball, 2000). Stress and emotional difficulties often relate to concerns about the state of the patient upon transfer, nurses are unsure about what to expect in terms of level of the acuity or stability of the patient. Hall-Smith et al. state that ward nursing staff found caring for ICU patients stressful, although this was not elaborated on, whereas Griffiths and Jones (2002) comment that ward staff are often apprehensive about receiving patients from ICU, especially if still moderately nurse-dependent by ward standards. Griffiths and Jones suggest that few ward staff welcome a patient transferred from ICU as they find them too demanding after being exposed to one-to-one nursing care where nursing staff are always visible.

Whittaker and Ball (2000) believe that the level of experience of the nurse receiving the patient plays a significant factor on stress levels, where junior staff commonly experienced more negative feelings. Receiving patients from ICU creates anxiety and concern for senior staff as well, as it impacts on staffing levels and skill mix, ultimately affecting the care of other patients, and creates apprehension for them with junior staff managing complex ICU patients (Whittaker \& Ball). Senior nursing staff are the ones that accept patients from ICU (alongside medical staff), making decisions and ultimately having control over nursing staff workload. This can create additional stress for staff having to take an additional patient, as they feel pressured to take patient transfers and have little control over the transfer process (Haines, 2001). Receiving patients from ICU can take time, adding to staff stress levels when also trying to provide care for other patients, potentially impacting on the quality of care delivered to other patients. 
Patient-nurse relationships were identified as a significant factor in Haines (2001) study that addressed the difficulties faced by ward staff when caring for patients transferred from ICU. This discussion focused on continuity of care; with suggestions such as pre-transfer visits from ward nurses were recommended so that patients' and families' had a sense of familiarity post transfer. Pre-transfer visits are recommended within various studies (Cutler \& Garner, 1995; Leith, 1998; McKinney \& Melby, 2002; Saarmann, 1993) as highlighted earlier in the chapter. Another suggestion was the follow-up of patients and families, which was considered important and beneficial to patients due to the nature of the relationship already established with ICU nurses as part of one-on-one nursing care. Follow-up also provides support to ward staff as it acknowledges that ward staff often contact ICU for advice when faced with concerns regarding patient care (Haines, 2001). Followup of patients' and their families' often occurs informally by nurses in order to ensure that patients' and families' needs are understood and met (Benner et al., 1999). This frequently occurs within the context of the study setting ICU, particularly as it is often the only way to hear of a patient's progress. Follow-up services are mentioned throughout the literature in relation to intensive care, provided in various contexts such as follow-up outpatient clinics, ICU Clinical Nurse Specialists, ICU Liaison Nurse or Critical Care Outreach Teams, all of which are designed to support acutely ill patients beyond the boundaries of ICU (Chaboyer et al., 2005; Department of Health, 2000; Haines, 2001; Hall-Smith et al., 1997; Russell, 1999). Follow-up services, moreover, have been shown to complement the work of intensive care and improve the speed and quality of recovery (Department of Health, 2000). 
Having the appropriate knowledge and skills to care for these patients postICU is an important factor when receiving patients from ICU. Often a staff nurse's level of experience pre-determines allocation of patients transferred back from ICU, for example, caring for patients with tracheostomies requires specific skills and knowledge. Commonly, it is a matter of exposure to different patient groups in order to become more confident and competent. This lack of knowledge and skills can extend to the use of medical equipment, where obtaining or using appropriate medical equipment can cause difficulties for staff and may even lead to errors (Haines, 2001). Within the UK, educational sessions have been designed to teach ward staff some of the aspects of critical illness in order to care for more complex patients post-ICU and create a greater appreciation of monitoring of patients in their care (Haines \& Coad, 2001).

Communication at all stages is highlighted by Whittaker and Ball's (2000) study, which looked at the experiences of ward staff receiving patients from ICU. According to Whittaker and Ball communication and information need to be appropriate and relevant whether it be telephone information, verbal handover, or regarding equipment needed and paperwork. Indeed, documentation was seen as a key aspect in providing continuity of care. Documentation such as fluid balances, medications and observation charts were also seen as vital (Whittaker \& Ball). Whittaker and Ball recommend that telephone information is brief, and include the level of dependency of the patient and equipment required, and that the nurse caring for that patient should be the contact person in order to ensure a more thorough handover. A trap that ICU nurses succumb to is giving too much detail to remember or irrelevant information when giving verbal handover. Sometimes this information can be in a language that is foreign to ward nurses, such as terminology like 
metabolic alkalosis. Atwal (2002) proposes that if nurses do not comprehend the information they are given as part of handover then they do not question it, potentially allowing adverse events to occur during a patient's hospital admission.

Whittaker and Ball (2000) outlined factors such as documentation, assessment, dependency, and workload as important information in order to provide appropriate ongoing nursing care for patients. The documentation of significant events or main problems experienced by the patient during their ICU admission was considered a major factor in order to facilitate ongoing nursing care (Whittaker \& Ball). Another suggestion included patient assessment by a senior ward nurse prior to transfer to promote continuity of care; this practice is occasionally carried out by CNL from the ward within the study hospital already.

Whittaker and Ball (2000) propose that an indication of patient dependency would be valuable, in order to assist staff to determine the level of intervention needed. A dependency score assists in planning nursing workload and staffing needs. This may include a Waterlow/Braden score (pressure area risk), assessment of mobility or their ability to transfer and the number of nurses to assist. Although, mobility of ICU patients is often difficult to assess as a significant portion of their ICU admission has been bedridden due to their acute health status. Consequently, mobility/transfer assessment is a skill that ICU nurses may perform inadequately. ICU nurses can assist with decreasing patient dependency on nursing care and technology by reducing non-essential monitoring and decreasing nursing care and presence prior to transfer (Cutler \& Garner, 1995; Saarmann, 1993; Whittaker \& Ball, 2000). Saarman emphasises that monitors should be turned off ahead of transfer so that the patient can experience this while still in a safe and familiar environment. 
Families can create additional stress for ward nursing staff. Relatives often exhibit increased negative feelings or increased anxiety related to the transfer of their loved ones when experiencing a swift withdrawal of intensive care, a decrease in nursing presence, or no noticeable change in the patient's condition (Whittaker \& Ball, 2000). Consequently, ward staff are often faced with providing psychological support not only to patients but their families as well. This can be exacerbated by the fact that patients and their families have little awareness and understanding of the nurse’s current workload and patient allocation (Cutler \& Garner, 1995).

Haines and Coad (2001) and Whittaker and Ball (2000) recommend that relatives visit the receiving ward prior to patient transfer in order to become familiar with the environment and nursing staff in an effort to help reduce anxiety and create an appreciation for the differences between the two areas. Pre-transfer booklets are another way of introducing the ward to the family and reducing anxiety, as discussed earlier in the chapter. Such recommendations enable patients and their families to have an appreciation of the ward environment prior to be transferred, understanding that nursing care will be somewhat different, and ideally, a better understanding of the ward nurses workload. Consequently, minimising any added stress for ward nurses, as families are often perceived as an additional stress. It is also essential that ICU nurses promote transfer to the ward as a positive step towards recovery to enhance patients' and families' perceptions of the continuity of their care and progression towards hospital discharge. Saarman (1993) also points out that ICU nurses should create a positive picture of other nurses within the hospital so that patients can be assured that ward staff have the expertise to care for them efficiently. 
Other general problems experienced by ward staff include a lack of resources, predominantly related to staffing, skill-mix workload and patient's notes. Whittaker and Ball (2000) noted that the disorganised patient notes resulted in time wasting and potentially putting the patient at risk as information related to patient care was difficult to locate.

\section{Conclusion}

Transition as a concept is recognised as significant within the nursing discipline, particularly as nurses are often involved with patients and their families as they go through multiple changes throughout their hospital admission. As highlighted within the nursing literature, the transition from ICU to the ward environment can have a considerable impact on patients and their families, such as transfer anxiety and both physical and psychological responses. Hence nurses have an important role to play through nursing interventions and need to consider the patterns of allimportant transitions rather than concentrating on one specific type of transition. As such the emphasis on discharge planning needs to change so that ICU nurses can relate more to this process, making it more of a priority in their nursing care and perceive it as the transition of patients from one level of care to another, rather than traditional views where discharge planning destinations are to the community. Certainly, the benefits of discharge/transfer planning outweigh the arguments for a lack of discharge/transfer planning in ICU, as evidenced by improved patient and family outcomes, continuity of patient care and ultimately a smooth transition. 
However, once patients are transferred from ICU the ongoing nursing care of these highly dependent patients with multiple complex needs is provided in the ward environment and ultimately impacts on ward nurses, an area that has received little attention within the nursing literature. As previously discussed within this chapter, ward nurses often experience difficulties with stress and emotions, patient-nurse relationships, lacking the appropriate knowledge and skills to care for these patients, communication issues, a lack of appropriate interventions in order to provide ongoing care for the patient, difficulties with families and general problems such as a lack of resources.

Little nursing literature has explored the phenomena of ward nurses receiving patients from ICU. Whittaker and Ball (2000) and Haines (2001) studies have laid the foundation for further nursing research in this area. Both these studies were carried out in the UK. This phenomena needs to be explored in a NZ nursing practice context, where health care issues are similar, for example, shortage of intensive care beds, but hospital infrastructures differ. This thesis builds on the work by these authors and further explores the nature of receiving patients from ICU from a ward nurses perspective in order to understand the issues faced by ward nurses and to inform nursing practice within NZ.

In order to examine this further, a qualitative descriptive study was carried out to explore - 'The transition of patients from ICU to the ward from ward nurses' perspective, as discussed in the following chapter. It aimed to explore the experiences of ward nurses, in particular identifying any areas of concern, highlighting specific problems that occur on transition and to address what information is pertinent to ward nurses upon transfer within the within the study 
setting. The following chapter further discusses the research methodology and methods utilised to carry out the above research question. 


\section{Chapter 4: Research Framework, Methodology and Methods}

As the previous chapter has detailed, in the past, the attention has been on the experiences of patients and their families transferring from ICU and the effect that discharge planning from ICU to the ward has had on them. Minimal nursing literature has been written regarding the experiences of ward nurses receiving patients from ICU. This research further examines 'the transition of patients from intensive care to the ward environment from ward nurses' perspective. A qualitative descriptive methodology was used to explore and describe the ward nurse's experience, expectations and issues thereby gaining insight into the research topic.

Focus groups were selected as a means to explore the ideas, opinions and insights of ward nurses regarding this research topic. An overview of focus groups is discussed, supported by their history and advantages and disadvantages. The research design is detailed including the recruitment process, the focus group interview process, data analysis, ethical implications and rigour.

\section{Research question}

What are the experiences and issues/concerns from ward nurses when receiving patients from the intensive care unit?

\section{Research aims}

The specific aims of this research included:

- To explore the experiences of ward staff when receiving patients from ICU.

- To identify any issues/concerns that occurs when receiving patients from ICU.

- To highlight specific problems that occur on transition from ICU to the ward.

- To address what information is pertinent to ward nurses upon transfer. 


\section{Methodology}

This research utilises a qualitative descriptive design. Such a design is suited to areas of investigation of human endeavour where little previous research has been undertaken. According to Sandelowski (2000) qualitative descriptive designs typically are:

...an eclectic but reasonable and well-considered combination of sampling, and data collection, analysis and re-presentational techniques...Qualitative description is especially amenable to obtaining straight and largely unadorned (i.e. Minimally theorized or otherwise transformed or spun) answers to questions of special relevance to practitioners and policy makers. (p. 337)

The present study aimed to describe the transition of patients from intensive care to the ward environment from ward nurses' perspective'. In keeping with a qualitative descriptive methodology this study aimed to describe this area of interest in a way that clearly describes the event in the everyday terms of that event and in ways that the participants can recognise as their experience (Sandelowski, 2000). Whilst other data collection methods in qualitative descriptive research exist, focus groups are particularly suited as a data collection method in this approach as they allow feedback and consensus on the description of the event to be developed with the participants. Focus groups can be considered the qualitative descriptive equivalent of the quantitative survey (Sandelowski).

Focus groups were used as a means to explore the experiences and issues/concerns/expectations of ward nurses when receiving patients from ICU. 
Focus groups were also chosen as the method of choice as this is a small piece of scholarly work done within a short time frame and with limited resources available to the researcher. Focus groups allow for group interaction to occur in order for ideas to emerge from the group; therefore having the ability to become "more than the sum of their participants, to exhibit a synergy that individuals alone cannot achieve” (Krueger, 1994 p. 45). Consequently, focus groups were the method chosen as insights, experiences and opinions of ward nurses receiving patients from ICU were needed to complete this exploratory research. Focus groups as a method of data collection are explored below.

\section{Focus groups}

The use of focus groups is a qualitative approach alongside case studies, ethnographic research and participatory models of research (Mertens, 2003). Focus groups employ a group interaction process to collect and sort data on a topic determined by the researcher (Morgan, 1996). Though focus groups are a type of group interview, different processes distinguish them. Morgan identifies three vital components: focus groups are a research method dedicated to data collection; they establish the interaction in a group discussion as the source of the data; and finally they recognise the researcher's active role in creating the group discussions for data collection.

Focus groups involve a gathering of people who have a perspective on a particular research topic, who are chosen deliberately for their knowledge and insight in the area in which the research relates (Roberts \& Taylor, 2002); in this case for their ability to describe their experience of the transition of patients from intensive 
care to the ward. Focus groups are used to create 'focused' interviews, involving up to twelve people, as a homogeneous group (Grbich, 1999; Johnson \& Turner, 2003). In this case, the participants were Registered Nurses (RN's) working at the study hospital in the ward environment that receive patients transferred from intensive care; and have given their consent to be involved.

\section{History of focus groups}

Group interviews are noted as early as the 1920’s within the social sciences arena. Robert Merton's work in the 1950's set the domain in focus groups, determining many of the common practice applications seen as relevant in conducting focus groups. Morgan (1998, as cited in Madriz, 2000) describes the development of focus groups in three phases. Firstly, in the 1920's, where social scientists developed non-directive interviewing using open-ended questions, thereby allowing greater freedom in participants’ responses. Secondly, Morgan (1997) states group interviews occurred post World War II in the 1970's as a means to examine the persuasiveness of propaganda efforts, to measure the effectiveness of training materials for troops and were used in studies on work productivity and market research.

The third phase (Morgan 1998, as cited in Madriz, 2000), from the 1980’s to the present, where focus groups are now used by various professionals including health professionals, to conduct qualitative research on a diverse range of issues. In nursing as such, focus groups are used in both clinical and education settings. These include exploration of why Enrolled Nurses (EN) have not taken up conversion course opportunities (Webb, 2002), to assessing employer evaluation of graduates 
(Howard, Hubelbank \& Moore, 1989) and differentiation made by emergency nurses of non-cardiac chest pain from panic disorder (Hamer \& McCallin, 2006).

\section{Advantages and disadvantages of focus groups}

One of the main advantages of focus groups is their ability to generate concentrated data through spontaneous exchange of ideas, thoughts and opinions (Morgan, 1996; Morgan, 1997; Nyamathi \& Schuler, 1990). In the present study it was felt that the group interaction and group dynamics of focus groups would enable a thicker description of the experience being described in a way that individual interviews could not.

Not only do focus groups provide insight into people’s perspectives, they can also offer insight into the power of group dynamics and the sources of complex behaviours and motivations. A unique feature of focus groups is the researchers ability to observe group interaction, as participants engage with one another, querying and explaining themselves to each other, and have a tendency towards consensus around the research topic.

One of the main disadvantages of focus groups is that their findings cannot be routinely projected to the larger population (Hansler \& Cooper, 1986, as cited in Nyamathia \& Schuler, 1990) due to the nature of focus groups providing in-depth insight in a particular context that does not allow generalisations that extends beyond that context (Sim, 1998). Another disadvantage is the potential for the moderator/researcher of the focus group to influence data generation and the impact they may have on the group itself. In the researcher's efforts to guide focus group 
discussions, the result can be a disruption to the natural interaction of the group dynamics.

Within focus groups there is the potential for 'public' rather than 'private' viewpoints to be heard rather than participants’ individual ideas (Grbich, 1999). This occurs when dominant members of the group control the discussion; consequently less vocal members can be overlooked. In this current study ground rules were put in place to establish the importance of hearing from everyone, this is elaborated on further in the focus group interview process. A summary of the advantages and disadvantages of focus groups adapted from the findings by various researchers is detailed in Table 3. 


\section{Table 3: Advantages and Disadvantages of Focus Groups}

\begin{tabular}{|c|c|}
\hline ADVANTAGES & DISADVANTAGES \\
\hline Time efficient & Less vocal members can be overlooked \\
\hline $\begin{array}{l}\text { Can obtain in-depth information about } \\
\text { exactly how people think about an issue }\end{array}$ & $\begin{array}{l}\text { Only a limited number of questions can be } \\
\text { asked }\end{array}$ \\
\hline Facilitates discussion among participants & $\begin{array}{l}\text { Findings cannot be generalised to a larger } \\
\text { population }\end{array}$ \\
\hline $\begin{array}{l}\text { Ability to collect data from many people } \\
\text { in a short time frame. }\end{array}$ & $\begin{array}{l}\text { Some people do not interview well in } \\
\text { group situations, while other tend to } \\
\text { dominate }\end{array}$ \\
\hline $\begin{array}{l}\text { Allows observation of group and degree } \\
\text { on tendency towards consensus on } \\
\text { particular topics }\end{array}$ & Responses may not be as rich as hoped \\
\hline $\begin{array}{l}\text { Suitable for groups with strong oral } \\
\text { tradition }\end{array}$ & Facilitator needs specialist skills \\
\hline $\begin{array}{l}\text { Group participants have opportunity to } \\
\text { hear diverse opinions }\end{array}$ & Questions cannot be explored in detail \\
\hline Allows most content to be taped & Interviewer or facilitator bias \\
\hline $\begin{array}{l}\text { Group provides instant verification of the } \\
\text { data }\end{array}$ & $\begin{array}{l}\text { May be dominated by one or more } \\
\text { participants }\end{array}$ \\
\hline Have high face validity & Data analysis may be time consuming \\
\hline
\end{tabular}

(Beyea \& Nicoll, 2000; Grbich, 1999; Johnson \& Turner, 2003; Madriz, 2000; Morgan, 1996; Nyamathi \& Schuler, 1990). 
Generally, three focus groups is the rule of thumb or as many as necessary until saturation, (the point where no new information or ideas are forthcoming) is reached (Krueger \& Casey, 2000). Usually the first two focus groups provide considerable information. As the researcher I used this principle as a guideline for my research. The decision to conduct two focus groups initially was also influenced by time constraints and an attempt to confine the amount of data to be analysed. Three focus groups were finally conducted for this research, each with a maximum of ten Registered Nurses (RN) interested in sharing their experiences/concerns when receiving patients from ICU. Sessions for the focus groups were sixty to ninety minutes in duration. The focus groups were run on hospital campus to enable easy accessibility for nursing staff and provide a neutral yet familiar environment to facilitate discussion.

As part of the research design, a moderate level of standardisation occurred between the focus groups, that is the degree to which identical questions and procedures occurred. For this research, standardisation featured to maintain consistency in the process conducted within all focus group discussions, particularly due to an awareness of time restraints with ward staff being able to leave the wards. However, standardisation still allows for minor variations to encompass the unique aspects of each group (Morgan, 1996). Standardisation facilitates a high level of comparability between focus groups enabling easier analysis of the data. Nevertheless, a less structured approach is deemed more appropriate for exploratory research as strict standardisation can be restrictive on the exploratory nature of focus groups (Morgan, 1997). 


\section{Recruitment process}

Initially, various wards with the greatest links with ICU within the hospital were approached to create awareness of the research. This included the following wards: surgical, medical, paediatrics, plastics, cardiothoracics, orthopaedics, and the high dependency unit (HDU). A review of discharge destinations from intensive care over the last six months identified one common ward from each of the above specialities. Contacting wards with the greatest links to ICU was about creating 'context' in terms of the common discharge destinations where ward nurses had the greatest contact with receiving ICU patients in order to engage with potential participants. This method of sampling is in keeping with a qualitative descriptive methodology where purposeful sampling is used to obtain participants who are information rich for the purposes of the study (Sandelowski, 2000).

Clinical Nurse Leaders (CNL) from the most common wards were sent letters and approached to explain the research, offered in-service sessions and asked to put up flyers to facilitate the process of engaging with wards and establishing communication links (Appendix I \& II). In-services were offered in these areas in order to explain the purpose of the study, create awareness and facilitate recruitment of $\mathrm{RN}$ to participate in the focus groups. Flyers were also displayed on notice boards and within communication books in each of these wards, with contact details of the researcher. Letters and flyers were sent to all other non-common wards, including coronary care unit (CCU), within the above specialities via the internal mail. It was anticipated that participants would self-recruit from the advertising phase. CNL were followed-up via telephone the day prior to remind them of the intended focus group session, as recommended by Krueger and Casey (2000). 
The participants in this study where chosen based on their occupation as nurses from a variety of wards, thereby providing sufficient variation among participants to allow for different opinions/ideas. Typically 6 - 12 participants are used for focus groups. Krueger (1994) suggests that groups larger than 12 participants tend to create fragmentation within the group. Consequently, smaller group sizes were chosen to encourage higher levels of participation, to enable participants time to share their insights, be large enough to provide diversity and overall easier for the researcher to manage in regard to size and high levels of engagement (Morgan, 1996; Krueger, 1994). Therefore, up to ten RN was the maximum number proposed for each of the focus groups in this research, with a minimum of five RN.

\section{Inclusion and exclusion criteria}

The following criteria were adopted in the recruitment process:

\section{- Inclusion Criteria}

a. Registered Nurses (RN)

b. Works in one of the following wards: high dependency, plastics, surgical, medical, cardiothoracic, orthopaedics and paediatrics.

c. Interested in exploring the transition of patients from intensive care to the ward environment.

\section{- Exclusion Criteria}
a. Agency nurses
b. Student nurses.
c. Registered nurses with less than six months post-registration experience. 


\section{Recruited participants}

A total of three focus groups were conducted with a total of nine participants overall. Three focus groups were held in order to recruit sufficient participants to enrich the data collection. It was initially anticipated that a larger number of participants would be recruited to the study however, despite initial high interest fewer nurses than anticipated participated in the study. The focus groups included ward nurses from the following areas: cardiothoracics; plastics; high dependency; surgical; medical; and coronary care. The first group consisted of nurses from coronary care and surgical $(n=2)$; the second group consisted of nurses from cardiothoracic and plastics $(n=3)$; and the third focus group consisted of nurses from medical and high dependency $(n=4)$. The focus group sessions lasted 45 to 80 minutes depending on the number of participants within the group.

The groups were homogenous in terms of ward nurses working within the study setting and predominantly female (there was one male participant) due to the nature of the nursing workforce; this factor was not premeditated in the research design. Predominantly participants were of New Zealand European ethnicity, with one exception that was Indian in ethnicity. There was no attempt to maintain homogeneity with regard to gender or ethnicity; all groups were heterogeneous in terms of age.

\section{Focus group interview process}

Data was collected using a focus group process. At the beginning of each focus group the researcher welcomed the participants, introducing the facilitator (researcher) and the assistant facilitator and explained their roles. As the researcher 
and facilitator of the focus groups I disclosed my background knowledge of the research topic, my role as a nurse, professional respect for my colleagues and that it was my research. I emphasised my role as the researcher/student in this process and not an ICU nurse so that participants felt comfortable and open to sharing ideas, feelings and opinions with the researcher. Krueger (1994) acknowledges that when selecting a facilitator/moderator they should have adequate background knowledge on the topic of discussion to place all comments in perspective, and be able to communicate clearly and precisely; participants should feel comfortable with the facilitator to allow open discussion and that the facilitator is the appropriate person to ask the questions. The researcher's role as the facilitator focused on directing the discussions, keeping the conversation flowing, encouraging equal participation and taking notes on the whiteboard. This level of facilitator involvement is described as moderately structured, whereby the questions are predetermined that guide the discussion and, in managing the group dynamics, the facilitator encourages everyone to equally participate in the discussion (Morgan, 1996). Morgan however, recognises that there is very little consensus about what comprises a more or less structured approach to questioning.

As part of a team approach an assistant facilitator was present during all three focus groups and was considered a neutral person (with no direct benefit from the study or influence over the participants or researcher) during the focus group with no direct participation in the discussion (Krueger, 1994; Krueger \& Casey, 2000; Nyamathi \& Shuler, 1990). The assistance facilitator was the ICU Research Nurse whose role consisted of taking detailed notes, operating the tape recorder, responding to unexpected interruptions such as latecomers and noting participant's body language throughout the discussion (Krueger, 1994). As part of this role an Observer 
Confidentiality Form was signed (Appendix III). The assistant researcher also participated in the post focus group debriefing, which was not audio taped. Debriefing between the researcher and the assistant researcher allowed for first impressions to be captured, going over written notes taken, discussion of group dynamics and making general contrasts between each of the focus group sessions (Kruger, 1998).

\section{Focus group preparation}

An overview of the research topic was given to the participants outlining the purpose of the research and the intended process. At this stage participants were then asked to read an information sheet and sign a consent form (if this had not been done prior to the focus group). This process included ethical issues such as confidentiality and allowing time for any questions as required (Appendix IV). Ground rules were established as common courtesy, which were prepared by the researcher in the interest of time constraints and outlined to the participants, with the option of participants adding further to them. Ground rules were put in place to minimise some of the disadvantages of focus groups, such as dominance and less vocal people being overlooked. Ground rules acknowledge that everyone must be given the space to speak freely so only one person speaks at a time; no side conversations amongst neighbours; there are no right or wrong answers but rather differing points of view; and any information, comments and discussions in the group must remain within the group to encourage confidentiality (Morgan, 1997; Krueger, 1994). Other mechanisms put in place to minimise any risk to participants included: participants from a wide variety of areas; a minimum of two focus groups; a neutral person present during all focus groups; and an opportunity to meet individually with the 
researcher. Support and assistance was available from the researcher's supervisor should anything unexpected occur. Te Puna Oranga (Maori Health Service) was available for consultation relating to any Maori specific issues.

\section{Focus group process}

Participants were asked to introduce themselves, their respective wards and their interest in the research topic in order to engage participants one at a time in the group and act as an icebreaker. The objectives of the focus group were then reiterated to the group.

As discussed earlier the objectives of the focus were to

- $\quad$ 1. To explore the experiences of ward staff when receiving patients from ICU.

- 2. To identify any issues/concerns that occurs when receiving patients from ICU.

- 3. To highlight specific problems that occur on transition from ICU to the ward.

- 4. To address what information is pertinent to ward nurses upon transfer.

Questions designed to elicit descriptions of the nurse's experience and explore issues and concerns related to each of the questions were then asked and group discussion facilitated by the research related to each objective ensued.

In relation to objectives 1 and 2, participants were asked to 'think back' to receiving a patient from ICU and what was the experience like; 'think back' questions ask participants to reflect on their personal experiences, encouraging 
specific and grounded responses based on their experience and establishing a context for their response (Krueger \& Casey, 2000).

In relation to objectives 3 and 4 a solution-focused approach, as described by Walsh, Moss and Fitzgerald (2006) was utilised. The participants were prompted to use their imagination to imagine that a miracle had occurred and an 'ideal' transfer process now existed. They were then asked to describe what would be different to what now exists. This technique is similar to that described by Kruger and Casey (2000) to elicit from participants how things could be different or provide answers to a problem. This process allowed ward nurses to describe the things that they felt were important to them.

Notes were written on the whiteboard by the researcher from both types of question approaches and utilised alongside the raw data (taken by the assistant facilitator). In addition to the written notes, all focused groups were (with the permission of the participants) audio taped to assist in later data analysis (see section below on data analysis).

Participants communicated and interacted well with one another despite coming from different specialities with slightly different issues and concerns that occur as part of the transfer process. The majority of concerns were similar for different areas and this allowed ideas to bounce off one another and stimulate discussion, whilst also acknowledging the differences. Humour came through during discussions due to the similarity between experiences, with an underlying understanding between participants of how it is in the work place, which the researcher was able to appreciate with them. Participants acknowledged the ground 
rules put in place for discussion and supported them. Occasionally the group discussion would get slightly off track, involving engagement of the researcher to refocus the discussion. Participants' body language appeared open and friendly, supported by the open seating arrangement and the neutral location to facilitate an open discussion with limited barriers. The common denominator that supported the interest in the focus groups and the group dynamics was that they were are all ward nurses who received patients from ICU.

At the end of each focus group participants were asked to validate notes taken on the whiteboard in order to verify the summary of comments, a method recommended by Krueger and Casey (2000). These notes were written down after the focus groups as part of data collection. Group consensus was sought as to the degree to which the summary of comments reflected the experience and concerns of the participants in relation to the study question and the focus group objectives. Participants were thanked for their time and support; a certificate of participation was presented to each nurse in recognition of this, which they could add to their nursing portfolio if desired.

\section{Data analysis}

The focus groups aimed to generate a consensus on the experiences and the key issues for ward nurses when receiving patients from the ICU. Further qualitative data analysis occurred within this study where key issues and experiences from all the focus groups were analysed and descriptive themes evolved (Creswell, 2003). Analysis of the data included categorising responses in terms of the questions, thematic analysis - identifying themes (explicit and implicit), essences or patterns 
within the text, further analysis into sub themes and the collation and labelling of themes.

It is acknowledged that there is no such thing as pure description and that all description entails (to a lesser or a greater degree) interpretation (Sandelowski, 2000). It must be acknowledged that I am an intensive care nurse and the data analysis must to some extent be influenced by this fact. Nevertheless, the process of data analysis described below endeavoured to be as much as possible "data derived" in so much as whilst it was a systematic process, the emerging themes were reshaped to accommodate new data rather than have pre-existing codes applied (Sandelowski).

This approach to data analysis was chosen due to the iterative nature of the focus group process. Whilst the group discussion was framed with pre-determined questions as outlined above - the group process was such that the description of issues of concern and experiences of transition were discussed simultaneously or at least discussion of one often led to thoughts on the other. The themes presented in the findings therefore reflect this integrated nature to the experience of transition and will not be broken up into themes around each of the focus group objectives.

Initially during data analysis, the note taking (whiteboard and research assistant note taking) data was re-read several times, in conjunction with listening to the audiotapes in order to generate general impressions. The audiotapes of the focus groups were not transcribed. A long table approach (low technology option using a long table) as a way of making concrete analysis was used with the note taking data, to allow identification of themes and categorise results (Krueger \& Casey, 2000). The core elements of this approach are basically cutting, sorting and arranging 
through comparing and contrasting. Note based transcripts were cut apart, marking with coloured pen the responses in terms of the two question approaches and sorted together with comments that were similar, and then arranged through comparing and contrasting in order to create categories. The audiotape data was utilised to clarify the notes and quotes as necessary. Sub themes were then developed from the categories, where descriptions from the text were used to label themes with which ward nurses would associate. Selected quotes were used within the thematic analysis to capture the essence of what was said within the focus groups from the audiotape data.

\section{Ethical implications}

Ethics approval was sought and obtained from the Northern Y Regional Ethics Committee (Appendix V). Written informed consent was obtained at the beginning of each focus group. This outlined the purpose of study, their rights, issues surrounding confidentiality and the benefits of the study (Creswell, 2003). Consultation occurred with Te Puna Oranga (Maori Health Service) via a submission to the Kaumatua Kaunihera Research Committee. The Kaumatua Kaunihera Committee supported this research subject to an ethnicity data collection space being added to the consent form as per the Ethnicity Data protocols for the Health and Disability Sector (Ministry of Health, 2004) (Appendix VI). In order to maintain the privacy and identity of the study setting, and the participants, any reference to the study setting hospital has been removed from this thesis and any referencing. 


\section{Rigour}

Rigour within qualitative research relates to the stringency in conduct that is used to ensure successive steps are undertaken with meticulous attention to detail and to ensure the research findings can be relied upon as reflecting the 'truth' of the matter (Roberts \& Taylor, 2002). This exploratory qualitative descriptive research sought to describe the experiences of ward nurses receiving patients from ICU. Qualitative descriptive research was chosen as straight description of phenomena was desired to ensure descriptive validity (Sandelowski, 2000).

Systematic processes were used for conducting the focus groups, data collection, data handling and data analysis. Field notes and audio taping were used to capture participants' comments, which were then reviewed and used in the analysis process. Systematic steps in the analysis were used to identify key themes and then compared with other results to identify patterns. For each systematic process an established trail of evidence can be verified.

According to Krueger (1994), focus groups typically have high face internal validity due to the believability of the comments from the participants. Procedures put in place to ensure the trustworthiness of the results within this research included: facilitating the focus groups myself due to my understanding of the research interest; participants being carefully listened to, with clarity being sought on any areas of ambiguity; and at the end of each focus group participants were asked to validate notes taken on the whiteboard in order to verify the summary of comments. These processes to ensure internal validity and hence trustworthiness are recommended by Krueger and Casey (2000). The researcher is therefore confident that the findings are 
a true reflection of what the focus group participants said, therefore ensuring credibility of the research. Credibility in this context is the extent to which participants of the research recognise the experience described within the research (Roberts \& Taylor, 2002). The focus group research method was therefore best suited to explore the experiences of ward nurses receiving patients from ICU in order for them to accurately reflect on how they felt and thought about the research topic and to ensure overall trustworthiness of the results.

\section{Reflection on the research process}

Recruitment presented one of the biggest challenges and is one of the difficulties of undertaking research in a clinical context. Non-participation is a common problem in focus group research (Howard, Hudelbank \& Moore, 1989; Webb, 2002); especially research involving health care professionals. The reduced number of participants within the first two focus groups resulted in a third focus group being conducted in order to enrich the data collection. Nevertheless, despite their small size, the researcher conducted all the groups as focus groups, as recommended by Morgan (1997) and Krueger (1994) in order to reduce any risk to the research process. The reasons perceived for limited participation in this research were staff being unable to leave the ward due to workload commitments or wards being short staffed. McLafferty (2004) proposes that it is very problematic bringing together a sizeable group due to the nature of shift work patterns. Hence, shift work patterns also impacted on the researchers own ability to personally talk to CNL's and give in-services to wards. 
The recruitment process ultimately relied on self-recruitment of participants despite consultation with the ward CNL. Therein lies an issue in regard to the recruitment process: whether more time was needed to allow this to happen; or should it have been longer to enable more ward in-services to have occurred; or conducted differently, for example, contacting ward staff directly via human resources. A study by the American Lung Association’s Not-On-Tobacco Program also perceived recruitment time being too short as a barrier to the research process (Massey, Dino, Horn et al., 2003). The overall recruitment process very much relied on the initial contact (personal meeting, letter and flyer) of ward CNL and when follow-up contact calls were made to the CNL prior to the focus groups. Most CNL were very supportive and responded positively when approached initially and during follow-up calls.

\section{Conclusion}

Qualitative descriptive research allows inquiry of human endeavour where little research has been done before, particularly in relation to obtaining information that is of special relevance to practitioners. Focus groups were used as the method of data collection to obtain a broad range of information about events and to allow feedback and consensus on the experiences/issues of ward nurses receiving patients from ICU. Focus groups are considered a type of group interview and have various advantages and disadvantages, the main advantage being the spontaneous exchange of ideas, thoughts and opinions; although it is suggested that their findings cannot be routinely projected to the larger population, however some research literature debates this. Three focus groups were held due to recruitment challenges and to enrich the data collection. Consistency between all groups was maintained utilising a moderate 
level of standardisation and researcher involvement in the overall process. Participants included ward nurses that received patients from ICU within the context of study site. Data was collected via a number of sources, including note taking and audio taping with the help of a research assistant. In order to conduct this research, the Northern Y Regional Ethics committee and the Kaumatua Kaunihera research committee were consulted to gain ethics approval. Recruitment presented one of the biggest challenges to the research process, where non-participation is a common problem in focus group research.

The findings from the focus groups are presented in the following chapter. Data from the focus groups is presented as five themes using thematic analysis: patients as intensive care staff say they are; time to prepare the biggest thing; documentation as a continuation of patient care; they forget what its like; and family, a need to know about them. 


\section{Chapter 5: Findings}

Focus groups were used to explore the transition of patients from ICU to the ward from a ward nurse's perspective at the study setting hospital. The objectives of the focus groups were to explore and describe the perspective of ward nurses; to identify any concerns and expectations; to highlight specific problems that occur; and to address what information is pertinent to ward nurses upon patient transfer.

Five themes emerged from the focus group discussions. Communication was the most significant aspect in all five themes. Firstly, "patients as intensive care staff say they are” is discussed in regard to patients being as the ICU state they are, information sharing, and the verbal handover process. Secondly, "time to prepare the biggest thing” was perceived as important by ward nurses when receiving ICU patients, whereby nurses know what to expect when the patient arrives, know what equipment is required and the overall timing of the patient transfer. Thirdly, “documentation as a continuation of patient care”, this theme focuses on fluid balance and observation charts, medication charts and transfer forms. It is noted at this point that the terms "transfer forms" and "handover sheets" are used interchangeably. Fourthly, "they forget what its like" theme discusses aspects of staffing levels and having appropriately experienced staff on the wards both of which are common problems within the ward context. Lastly, the theme "families a need to know about them” recognises families as a part of nursing care and the transition process. 


\section{Emerging themes}

The following themes are derived from the descriptions of the transfer process and from the solution focused questions used in the focus groups. The major themes that came through during the focus group discussions were about the patient being as they say they are, time to prepare for receiving the ICU patient, documentation, they (ICU staff) forget what its like and family. Communication was the key aspect that underpinned all themes that emerged during the focus group discussions, evidenced by the overlap between some of the themes.

\section{"Patients as ICU staff say they are"}

The name for this theme came from the description of a situation from one of the ward staff, where a patient who arrived in the ward did not appear to be as the ICU staff stated they were. This was a recurring theme across the groups and reflected both the experiences of ward staff and their expectations and concerns that information on patients being transferred to wards be an accurate reflection of the patient's condition and state of care. This theme has two sub themes: information sharing and the verbal handover. These sub themes are based on the main sources of information that ward nurses receive in relation to patient transfer.

The participants stated that for ward nurses the patient ideally should be as the ICU nurse/coordinator says they are upon arrival to the ward, based on the information received prior to the patient transfer. For some ward nurses this was about basic nursing care being up to date prior to the patient arriving on the ward, to receiving a clean and tidy patient, or in regard to the transferring nurse having a 
thorough knowledge about the patient's nursing care. From an ideal perspective, basic nursing care being up to date was considered an essential element for ward nurses "where everything that should have been done for that patient at the time has actually been done”. This included medications, intravenous fluids, dressings, and accurate fluid input/output. A junior nurse described this level of information as important; a more senior nurse described this ideal as "intimately knowing about the patient, ... knows holistically about the patient, ... what they've been like, what's been given, what has been done, drug chart, lines, dressings." This type of information was further described as preferably coming from the nurse who has "actively been involved with the patient and looked after them"--- "able to talk about the patient and not just hand them over - i.e. read it”. This ideally would be the appropriate ICU nurse to transfer the patient to the ward.

Nursing information requirements described by ward nurses varied when discussing the ideal patient transfer. Senior nurses looked more at the 'bigger picture' as well as wanting to know the basic practical nursing issues as outlined above. More junior staff described predominantly wanting to know the latter. Sometimes the ideal level of nursing care received by the ward can be as simple as a "clean and tidy patient”. Occasionally patients can arrive on the ward in a disarray, where a nurse described this as "oh my gosh there is an hour's work here”, and ultimately adding to their already busy workload. One nurse described an actual experience where the "patient came down looking a mess" and they had to check with the ICU nurse to see whether the patient had had a wash or not. Consequently, the level of information sharing regarding nursing care is crucial in order to provide continuity of care but more so familiarity with the patient in order to provide a 'bigger picture' of the patient's progress as a whole. 


\section{Information sharing}

Ward staff described information sharing as a significant component of communication between wards when transferring patients; it needs to be thorough in order to plan for patient care, and actually needs to occur prior to the patient transfer. Ward staff also described situations where sometimes information about a patient could be vague or inadequate regarding crucial information, such as the patient has been agitated or confused thereby requiring restraints. A nurse expressed that information can be vague, ---“light on information”---, particularly regarding head injury patients who have recently been sedated or medicated in ICU and then wake up agitated in the high dependency unit. Another nurse expressed that "ICU nurses are so used to working in that environment that perhaps they have forgotten what our environment is", especially when giving information over the phone.

Their perception was that miscommunication occurs between wards and within wards, where nursing staff "do not get told a lot about the patient until they actually see the patient". Often, it is the ICU coordinator who organises the transfer of patients directly with the ward CNL. Occasionally this results in information not being relayed to the bedside nurse as described by one nurse. Ward nurses ideally felt that the ICU bedside nurse should speak directly to the ward bedside nurse regarding patient information and negotiating a suitable transfer time. However, it was recognised that the nurse needed to be reasonably experienced in order to given relevant information and that the ward coordinator/CNL needed to be informed in order to plan ward workload and staffing. 


\section{Verbal handover}

The participants described verbal handover between nurses as the main form of a communication as part of the transfer process. Nurses felt they relied considerably on a good verbal handover, especially when busy. It was consensus that the verbal handover process varied depending on the individual nurse, "sometimes it was good, sometimes incomplete". One nurse stated that a "bad verbal handover actually puts the ward nurse behind --- takes more time”; potentially due to the time it takes to settle the patient in and locate patient information within the medical notes. Ward nurses ideally felt the transfer process should be given appropriate time to effectively ensure a thorough patient handover, "so things do not get missed --- to give a good picture of the patient”.

Ward nurses stated that experience itself made it easier for nurses to receive patients from ICU as they know what to expect from the ICU nurse, know what to look for, know the right questions to ask and recognise the "difference between $a$ good and bad handover". One nurse commented that the level of experience itself impacted on "how you feel about taking back a patient from ICU”. The assumption can be made here that experience and confidence may be interrelated. Less experienced staff often did not question the ICU nurse's handover, forgetting to ask specific things; a junior nurse speaking up within one of the focus groups noted this.

The ward nurses ideal perspective on this part of the transfer process varied depending on the nurse; some preferred a bedside handover whereby “--- looking at the patient you can take a lot in and notice things, alerts you to ask questions there and then ---" and involve the patient in their care, while others preferred both a bedside and a sit-down handover away from the patient in order to discuss the patient 
properly and go through their nursing care step by step. An influencing factor mentioned briefly though not elaborated on was if you had a difficult family then you were more likely to have handover away from the patient. One nurse also expressed that if a patient is suitable for transfer they "theoretically" become a ward patient; hence the ICU nurse should have the time to know the patient thoroughly in order to give a proper handover. There appeared to be an expectation when describing their experiences that ICU nurses should know what is going on with the patient; "ICU nurses have a reputation as being onto it --- know what is going on" and therefore give a more concise handover.

Communication between nurses largely consists of information sharing via verbal processes. Ward staff rely on these processes in order to plan for patient transfers, provide ongoing nursing care and ensure continuity. Patients arriving on the ward in the condition stated by the transferring ward would be considered ideal by ward staff, whereby ward staff would know what to expect, this often meant basic nursing care actually been done prior to patient transfer.

\section{Time to prepare the biggest thing}

The title for this theme came from a nurse describing what would be 'ideal' as part of the transfer process when outlining the importance of knowing what type of patient the ward would receive from ICU. Time to prepare was reiterated during the focus group discussions regarding experiences of staff, where they felt that the time to prepare for patient transfers was inadequate. Time to prepare was considered important by the majority of ward nurses in being able to be organised for receiving a patient from ICU. Ward staff perceived that preparing for receiving ICU patients 
requires more time and input. One nurse described experiences as to why a bit of preparation was significant -

-- [in the] - ward itself - [a] - bit of preparation - [is useful] -- depending on the type of patient we receive --- bit of preparation when we hear the news that we are receiving a patient from ICU --- the difference being that the patient in ICU comes from a one-to -one nurse ratio to the ward where the nurse has five to six patients and out of that five, two to three other patients already need three to four hours of extra care. Many times we have that problem ---suddenly we get a patient from ICU, especially in the afternoon shift.

Communication before the patient arrives on the ward is crucial to allow nursing staff to prepare for receiving an ICU patient. It was recognised from nurses’ experiences that receiving ICU patients takes more preparation, requires more time and input, especially on initial arrival to the ward. Particularly for those wards who already have a high nurse-to-patient ratios, where the nurse already has "two to three other patients already requiring three to four hours of extra care”. It was acknowledged that this was not an issue for all areas as some have lower nursepatient ratios, for example, coronary care and high dependency and consequently, more time available for patient care upon transfer. One of the focus groups pointed out that a planned versus unplanned transfer does not always allow the ward time to prepare, especially if the ICU is "pressured for beds with more acute patients coming in”.

In order to prepare for the patient from ICU, ward nurses felt it would be ideal to know about the patient, their dependency level, know what the patient needs 
and know what to expect upon receiving the patient. This included specific information such as: dependency level, equipment required, restraints in-situ, whether a 'special' is required, patients Not For Resuscitation Status (NFR), or any specific family concerns. If it is a burns patient then part of that preparation needs to incorporate negotiation with ward nurses from plastics to have their dressing done prior to transfer. This essential type of information needs to be passed onto the ward nurses prior to patient transfer. Ideally, information that enabled nurses to be prepared was summarised eloquently by a more senior nurse and included "knowing what type of patient you're going to get, how intensive it is, the type of care they are going to need, and how much time it's going to take”.

One nurse expressed an experience where she was "un-informed about the severity of the patient's needs" resulting in feeling overwhelmed with a situation with a very distressed patient who needed ongoing BIPAP (biphasic intermittent positive airway pressure) post-transfer. This experience was exacerbated by the nurse not knowing the patient was on BIPAP prior to transfer and therefore not having the appropriate equipment ready upon receiving the patient. The acuity level of the patient was not known and being near the end of a busy morning shift, it actually required two nurses to receive the patient. This scenario highlights the need for accurate information to be given prior to patient transfer and the accuracy of that information in order for the ward to prepare for such a patient transfer.

Some of the participants stated that their experience was that some of the ward CNL "eyeball the patient" prior to transfer from ICU (pre-transfer visits) to the ward in order to allocate suitable experienced staff. Their experience was that this helped with providing a "clear cut picture of the patient", thus staff know what to 
expect, know what sort of patient they are going to get, and receive specific information such as invasive lines that are in-situ. A surgical nurse believed this current process worked well from their experience as it may highlight "something that is very important to us that may be a silly routine for ICU”. Pre-transfer visits by ward CNL was also deemed significant in being able to allocate appropriate ward staff to receive the patient based on their level of experience, whilst also ensuring an even workload of dependent patients amongst ward staff and those with relevant certifications such as epidurals, patient controlled analgesia (PCA) or central venous lines (CVL).

Equipment was essential in preparing for receiving a patient from ICU. Ward staff noted that they preferred to know if the patient required an infusion pump prior to transfer so that they could order it before the patient's arrival, especially as the hospital's equipment pool have limited supply. This also applied to PCA equipment. Communication regarding what type of equipment is required was considered important as part of the phone handover prior to patient transfer. If the patient required an air mattress, then during the transfer process appeared to be an ideal time to organise it in conjunction with the ward as opposed to transferring the "patient from ICU onto an ordinary bed then needs to be transferred onto air bed in ward”. For some wards the transfer process is easier as the same monitors and equipment are already there, this is the experience of nurses from the high dependency unit.

Communication regarding the time of the patient transfer was considered significant for ward nurses, although there appeared to be no consensus on a preferred time. Nurses from one focus group described their experiences in relation to the timing of patient transfers, where sometimes they could delay morning 
transfers, as nurses were often busy with morning cares. One nurse stated that "generally if patients come from ICU they require more input --- as used to one-toone nursing, where our workload is five/six patients." Her colleague further commented that "they have already discharged one patient to take a new one---a lot of work has gone on in between --- still chasing up on other four-five patients --- a lot to do in that hour before handover when you have a patient with high needs." Ideally, nurses felt late morning was more suitable as all the "morning cares are out of the way", or during the afternoon shift. Two o'clock was considered a "bad time" as nurses were preparing for the end of shift, writing up patient notes and getting ready for the ward nursing handover.

Ward nurses felt it would be desirable, whilst also important, to communicate any changes in the patient's status or any delays as part of the transfer process, and to ensure that the ward is satisfied with the arrangements. One nurse said that delays in patient transfer can have a "huge impact on how you manage the short amount of time you have got left to get everything else done --- the stress in itself not only for the nurse but also for the patient". The key point that arose regarding the timing of a patient transfers was negotiation between areas, especially as wards often have to discharge one patient to receive another. Generally wards felt that they were able to negotiate with ICU regarding a suitable transfer time.

\section{Documentation as a continuation of patient care}

In the focus groups, documentation in its many manifestations was an important and dominant element of the description of the participants experience and of their concerns and issues when receiving patients from ICU. Documentation was 
eloquently described by one nurse as a "continuation of patient care”, an important aspect in facilitating the ongoing care of ICU patients to the ward. The name for this theme came from this nurse's description.

Documentation was highlighted by the participants in a number of areas such as medication charts, fluid balances, handover sheets and overall organisation of paperwork. It was acknowledged that ICU documentation is different, particularly in relation to the recording of vital signs and fluid balances, which are all recorded on one large ICU 24-hour chart. Currently the 24-hour chart is taken back to ICU as part of the transfer process. Ward staff commented that "we are not getting a photocopy" or the "ICU nurse does not go through the 24 sheet". A major issue that wards found frustrating were the lack of accurate fluid balance documentation reflected in statements from participants like "input and out not there, only get totals, not hourly urine etc". There were two exceptions to this where certain wards receive the ICU 24 hour-chart as part of the transfer process, hence having a full record of input and output along with vital sign history. However, these two wards still have to transcribe off the ICU chart, which was described as time consuming. Consensus among the groups was that accurate fluid balances need to be fully transferred onto a ward sheet - i.e. from the beginning of a shift, along with the vital signs onto a ward observation chart.

The charting of medication was occasionally an issue for ward staff described from their various experiences. Ward nurses sometimes have to get medication prescribed once the patient is transferred to the ward, or get the patients medication reviewed post surgery, hence requiring them to locate a doctor. Charting of pain medication was a concern, where PCA prescription charts were not always available 
upon patient transfer. An example given by one nurse was where a burns patient had had intravenous morphine in ICU and there was no PCA morphine charted for the ward, and thus "it takes time for the pain team to chart stuff". It was felt that ICU doctors focus on ICU drugs and not the actual medications the patient requires. As one nurse said it is often not "what the patient needs -and this leads to the situation of having to chase up drugs from the team”. One focus groups member from a cardiothoracic speciality felt that intravenous fluids should ideally be charted in ICU prior to patient transfer, especially for cardiothoracic patients as per ward protocol, recognising that every ward has different concerns depending on their speciality. However, ward nurses shared an insight into the fact that ICU cannot cater to every ward's needs and protocols.

The majority of the focus groups deemed documentation as part of handover/transfer forms and within medical notes as insufficient. It was highlighted that ICU has a huge amount of documentation that makes it difficult to access important patient information in order to "carry out immediate cares". Ward nurses described situations where they are often unable to get to the patients notes straight away to clarify patient details or nursing care. One nurse described this as “paperwork in order prior to handover, --- from diagnosis through to fluids, ---so you don't have to flick through paper". Therefore, ward staff found it helpful if paperwork was in order as part of the handover process. Ward staff noted that there are occasions where there is are documentation deficits due to an ICU nurse having recently taken over the care of that patient, therefore not being completely familiar with the patient's treatment/history. 
It was perceived that the handover sheet did not cover everything the ward needs to know, such as a "summary of what has happened" or a "summary of the important points”, though it was subsequently acknowledged that the handover sheet is only as thorough as the person completing it. Surprisingly, a nurse from the medical ward commented that they did not receive transfer forms as part of patient transfer from ICU; her colleague supported this. One of the focus groups suggested that transfer forms should cover patient diagnosis, patient history, treatment, invasive lines, equipment, and general nursing care, particularly directed at the next four to six hours of nursing care post-transfer; to facilitate the ease of transition. A nurse recommended faxing this form prior to patient transfer in order to know what to organise in preparation for receiving an ICU patient. However, they did comment on finding the transfer form they received for the emergency department patients useful and suggested something similar would be helpful.

Documentation within the medical notes ideally should relate to patient care the ICU nurse had carried out prior to transfer, "what the patient had done that AM, for example, a wash" and a nursing plan of care, for example, patients with nasogastric tubes or dietary allowances/requirements. It was also felt that it was important to have a medical plan in place in order to direct future patient care, granted that this is a medical role not a nursing one. 


\section{"They forget what its like"}

The majority of participants in the focus groups felt that intensive care nurses forget what it is like to be a ward nurse and having to managing the complex needs of multiple patients. All focus group participants shared concerns regarding suitable staffing levels and appropriately experienced staff on the wards when managing ICU patients as part of the transfer process. The heading for this theme comes from a direct quote from two different nurses from two different focus group discussions.

Participants described the fact that wards have less nursing staff on afternoon shifts, many of them junior, creating a challenge for wards, particularly as ICU patients of high acuity are "more likely to be transferred in the afternoon". It was explained that sometimes only one person on an afternoon shift has the relevant certifications to care for an ICU patient, such as epidurals, PCA or CVL certifications. Often, the coordinator is the only one who has the relevant certifications, therefore having to take responsibility for various aspects of patient care as well as oversee the running of the ward. Participants stated that experienced ward nurses with suitable knowledge, skills and certifications are not always available on the wards to care for ICU patients. There was also the concern raised regarding the level of experience/skill of nurses receiving outlying patients in different specialities, as they may not know what to look for regarding the patient's medical condition.

Decreased staffing levels in the afternoon were also described as impacting on the feasibility of doing dressings, such as large burns dressings. This is an area that ideally should be negotiated with the plastics ward the day before or the morning 
prior to transferring the patient. The 'specialing' of patients was occasionally an issue experienced by wards, particularly if this information had not been communicated prior to transfer; hence the ward had not perceived this need, which "impacts on having enough staff to cope" or the ability to plan for an orderly 'watch', someone who constantly sits with the patient to ensure their safety. Senior ward nurses in the groups who also co-ordinate felt it was important to know the nursing hours or acuity level of a patient in order to plan ward workload and ensure the appropriate nurse for that patient's care. This was portrayed as important as part of the communication process "as the coordinator needs to ensure the right nurse for the patient, depending on the severity of the patient."

Most ward nurses felt that there appeared to be a "lack of understanding about what wards can take and actually manage" in regard to types of patients, lines, equipment, or even when giving information over the phone. One nurse commented that the nurse who receives the patient from ICU may not have had a lot of experience with lines, for example, CVL or may not have seen some piece of equipment/line for two or three months. This nurse further suggested that ICU staff "make assumptions about ward nurses knowledge and experience". Another nurse noted that it was almost as if ICU nurses had "forgotten what is like to work on the wards --- where care for more than one patient occurs, multiple dressings are done, old ladies are showered, blood results are checked, notes are written, and charting done for the next day, --- there's is something completely different”. Another aspect to this is the effect of transferring a complex patient to the ward environment, where they have 25 plus patients and one-to-six/eight nurse-patient ratios, where "consideration has not been taken into --- that patient hitting the ward is going to have on us". Ward nurses recognised that they are completely different areas of 
nursing, "ward nursing is not ICU nursing and vice versa", but as nurses we should have "professional respect for one another, trying to work together better". Ultimately, ward nurses recognised that there is the need for better understanding between areas, “---of what each ward does---workloads ---better communication”.

\section{Families a need to know about them}

Initially, families were not perceived as a major issue for nursing staff within the focus groups until further discussion came about in two of the focus groups. This became more evident during discussion of patient ratios in one focus group, where participants stated patients find it difficult to adjust to the ward environment. This issue of families also arose in another focus group, where one of the participant's family members had been a patient in ICU and a discussion about family issues ensured.

Some ward nurses perceived that patients were usually too unwell to be concerned about being transferred, “--- so ill they cannot even press the buzzer”. Others stated their experience was that some patients find the initial transfer difficult to adjust to for the first few hours, sometimes up to 24 hours, due to "being left alone with six other patients and nurses running here and there”.

Two of the focus groups agreed that families can be very nervous and anxious as the transfer of their loved one to another area comes with an "element of anxiety" and can be perceived as the "biggest transition". Ward nurses proposed that families could be worried that the patient is "not being cared for as well, as left alone" and 
that they take a "little while to adjust to a nurse not being at the end of the bed all the time”. Consequently, ward nurses recognised that it was about nursing families as well, where at "times you have to say you need to get off the floor for while", where ward nurses recognise that families can find it stressful seeing their loved one in hospital and need to be reminded to look after themselves.

Often, caring for families involves providing explanations to families, which a less experienced nurse stated she found frustrating as she did not always know the answers. Ward nurses also have the added responsibility to reassure the family that the patient is in a safe environment, as the family have often "seen their loved one been very ill --- life-threatening situation”. Interestingly though, caring for families was not perceived as an additional stress as ward nurses appear to accept it as part of their extended role. It was highlighted by a senior nurse that long-term patients were the ones that required a lot of reassurance upon transfer, otherwise perceived as "weaning from ICU”. One nurse stated that she found families had not been well prepared for transfer of their loved one from ICU to the ward and that perhaps ICU could prepare families a bit more as part of the transfer process.

\section{Conclusion}

This chapter explored the transition of patients from ICU to the ward from ward nurses perspective. In particular, looking at the experiences of ward nurses, their issues/concerns, parallel problems and pertinent information relevant to ward nurses upon transfer of the ICU patient. Five themes emerged from the findings, with the interweaving factor being communication. Basic nursing being done prior to 
patient transfer was an essential element for ward nurses, often sometimes seen simply as a clean and tidy patient. For ward nurses information sharing should be focused around the patient and their care and that the patient is as they say they are upon arrival to the ward. Information sharing also occurs as part of the verbal handover process, where ward nurses felt they relied significantly on a good verbal handover; although this process varied depending on the individual nurse.

Time to prepare was considered important for the majority of ward nurses in being able to be organised for receiving a patient from ICU; a process supported by providing accurate information about what to expect, pre-transfer visits from some ward CNL, ensuring the ward know what equipment to organise prior to transfer and negotiating a suitable transfer time; including any delays in patient transfer. Documentation was suitably described as a continuation of patient care. A major frustration experienced by ward nurses was the lack of accurate fluid balance documentation and vital sign history.

Ward nurses acknowledged that experience is significant in receiving patients from ICU as you know what to expect and often appropriately experienced staff are not always available; a factor often complicated by decreased staffing levels on various shifts. Ward nurses felt that there appeared to be a lack of understanding about what the ward can take and actually manage, where ICU staff often forget what it is like to work in a ward environment and acknowledge that other nurses' knowledge and experience maybe different. Ward staff also recognised that caring for families was part of their role, where some patients varied in their response to being transferred, whereas families required more assurance often due to anxiety. 
The following chapter discusses the findings and their implications for the transfer process. It also compares and contrasts the findings in relation to the literature regarding communication to a smooth transition; preparing to receive ICU patients; continuity of patient care; the other side of the transfer process; and families as a part of nursing care with a view to looking at where do the findings from this research sit in conjunction with the literature and what new nursing knowledge does it provide. 


\section{Chapter 6: Discussion}

This research explored the transition of patients from ICU to the ward from ward nurses perspective looking at the experiences, concerns and information requirements for ward nurses when receiving patients from ICU. Five themes emerged from the focus groups: patients as ICU staff say they are; time to prepare the biggest thing; documentation as a continuation of patient care; they forget what its like; and families, a need to know about them. Communication was a recurring sub-text in all areas. In comparing and contrasting the findings with the nursing literature, five broad areas of common concern became apparent: communication to a smooth transition; preparing to receive ICU patients; continuity of patient care; the other side of the transfer process; and families as a part of nursing care.

\section{Communication to a smooth transition}

Communication emerged as a common element and pertained to information sharing, the verbal handover and the timing of patient transfer; yet having a flow-on effect within the other areas. Good communication is pivotal to any successful patient transfer, accentuating its significance in the continuity of patient care (Whittaker \& Ball, 2000). Information sharing was seen as a major component of the communication process within this study no matter what format it takes, whether it is via telephone, verbally or written as long as it is concise and patient related. Ward nurses believed that the process of information sharing concerning patient transfer should ideally occur directly between bedside nurses in order to get a more thorough handover and to negotiate a suitable transfer time, a similar finding to Whittaker and Ball's study (2000). This same study also explored the experiences of 
ward staff when receiving patients from ICU, who reiterate that information shared prior to patient transfer, should enable the ward nurse to prepare the bed area for immediate care and any potential emergencies, for example, the patient with a tracheostomy. Whittaker and Ball further note that one of the negative aspects regarding information sharing is the giving of too much detail, such as irrelevant information. This is in contrast to the present research, where more information was deemed better than not enough.

Ward nurses within the present study ideally wanted the patient to be as the ICU nurse said they are. The theme of 'patients as ICU staff say they are ' may be linked to knowing what to expect upon receiving the patient from ICU, therefore ensuring the ward is well prepared based on the initial telephone handover information. This theme may also be seen as simply not adding to the ward nurse's already busy ward workload. For younger and perhaps less experienced nurses this ideally meant basic practical nursing care being done prior to transfer such as medications given, drugs charted and dressings done. On the other hand, senior nurses wanted to know the above as well as know the 'bigger picture', to holistically and intimately know about the patient in order to determine the patient's progress as whole, have a better understanding of their needs and the impact this will have on nursing workload. This expectation from ward staff about basic nursing care being done prior to transfer and having intimate/holistic knowledge about the patient is not discussed within the limited literature on this topic. However, this can be related to Whittaker and Ball's (2000) discussion of different information requirements or expectations based on experience of the nurse, where the focus regarding the patient is different. Whittaker and Ball's study suggested that ward nurses differ on the level of information they require depending on the experience of the nurse: for example, 
junior staff focus on a patient's condition, whereas senior staff were more concerned about the patient's long-term issues and their available resources to manage the transfer.

\section{Verbal handover}

Verbal handover is considered one of the key areas of communication as part of the transfer process. This has been identified within this study and recognized in other literature also (Rowe, 2001; Watts et al., 2005; Whittaker \& Ball, 2000). The verbal nursing handover plays a crucial role in the transfer of patient data, influencing the ongoing delivery of patient care and hence the continuity of care. Ward nurses in the present study believed that an inadequate verbal handover put ward nurses behind in their workload. This they felt was due to the time taken settling in the patient, locating patient information within the medical notes, and thus complicated by an already busy patient workload. Haines (2001) emphasises that it already takes time and experience to receive a patient from ICU, recognising that this adds to nurse workload pressures with the potential to cause staff stress. Consequently, an inadequate handover can add to this pressure. However, a poor handover appeared to be more of a frustration as opposed to an added stress within the current study.

A significant part of the verbal handover for ward nurses ideally is about taking the time to ensure a thorough patient handover in order to give a good indication of the patient's needs. This process varied between nurses, from a bedside handover to both a bedside and sit-down handover away from the patient. Within the literature this aspect of the experiences of ward nurses receiving patients from ICU is 
not identified. However, Rowe’s (2001) ethnographic study of nursing handover recognised the importance of including patients in the handover process, as is recognised within this research. Nevertheless, Rowe also highlights the difficulty in maintaining patient confidentiality at the bedside, where 'personal' information is candidly discussed in the ward environment (Webster, 1999).

\section{Timing of the patient transfer}

Another area highlighted within this study is the actual timing of the patient transfer. There was no consensus on a preferred time for patient transfer within this study, although late morning or during the afternoon seemed preferable. The underlying characteristic was communication and negotiating with the wards regarding a suitable transfer time. Not surprisingly, Whittaker and Ball (2000) see communication as crucial for any successful patient transfer. Delays in patient transfer were perceived as one of the few areas that ward staff considered stressful at times, impacting on nursing workload and available nursing time, creating stress for both staff and patients. However, the timing of patient transfer is not directly discussed within the literature. Nevertheless, this could be linked to Haines (2001) concept of a 'lack of control' over the transfer process and a feeling of inevitability, where her study describes these concepts as contributing factors to staff stress. Haines (2001) goes on to suggest that a sense of control is essential for ward staff when faced with receiving a patient from ICU.

Although not addressed within this study, the literature further recognises that the timing of patient transfers should ideally occur during daylight hours, as nighttime patient transfers often fare worse in relation to patient outcomes. Transfers at 
night or unexpectedly can cause patient anxiety, difficulty in coping with a new environment, increased confusion in patients, potential unexpected re-admission to ICU, and an increased risk of mortality (Duke et al., 2004; Leith, 1998; McKinney \& Melby, 2002).

\section{Preparing to receive intensive care patients}

Communication as part of the preparation process is vital in order for the ward to plan for receiving a patient from ICU. This research has revealed that the ICU patient group takes more preparation and require more time and input, especially for wards with already high nurse-to-patient ratios. This is supported by Haines (2001) study, which notes that it takes time and experience for ward nurses to accept patients from ICU. Ward staff within this current study emphasised that as part of that preparation process it was important to know about the patient, know what the patient needs and know what to expect upon receiving the patient. This uncertainty regarding a patient's severity was universal amongst ward nurses within this research. Suggestions were made by ward staff to assist in determining the dependency of the patient, such as activities of daily living (ADL), mobility, acuity, Braden Score (pressure area risk), and anticipated nursing hours (already part of staff/patient planning within hospital). Anticipated nursing hours that are entered into the hospitals 'one staff' database system to assist in staff planning and provide a forecast of the hospital's bed/patient status was suggested as a way of determining workload and managing appropriate patient allocation. Whittaker and Ball's (2000) study similarly recommended a dependency score (i.e. Waterlow Score - pressure area risk), an assessment of their mobility, and ability to transfer. These examples of patient acuity/dependency assessment tools assist in verifying the level of nursing 
intervention required in order to plan nursing workloads and approximate appropriate staffing requirements.

Often, premature transfers from ICU to the ward are commonly associated with creating bed availability for a new patient admission to ICU. Hence a planned versus unplanned transfer to the ward has an impact on the ward's ability to prepare for receiving the patient, as noted within the study. Due to the nature of the acute hospital setting, there are occasions when wards are required to take patients back earlier than expected due to bed demands for a new ICU admission, with no empathy for the impact this may have on ward staff. This occurrence is noted in Whittaker and Ball's (2000) study who suggest that a planned transfer is less likely to cause added stress for both ward staff and patients alike.

\section{Pre-transfer visits}

Pre-transfer visits were deemed helpful as part of the preparation process in receiving patients from ICU by ward nurses where this is current practice. Pretransfer visits from ward CNL/coordinators assisted ward staff in knowing what to expect prior to the patient arriving and assisted in allocating suitable staff to receive the patient from ICU. However, this is not standard practice as only a few CNL perform pre-transfer visits. Ward staff visiting ICU prior to patient transfer act as a way of facilitating continuity of care and encourages familiarity with nursing staff for patients and families when arriving on the ward is supported by various literature (Cutler \& Garner, 1995; Haines, 2001; Saarmann, 1993). Leith (1998) proposed that pre-transfer visits from ward staff benefited patients by reducing transfer anxiety. Transfer anxiety is a recognised concept that both patients and families may 
experience. It occurs when patients move from a familiar environment where they feel safe, to an unfamiliar environment (Coyle, 2001; Cutler \& Garner, 1995; Leith, 1998; McKinney \& Melby, 2002; Odell, 2000; Saarmann, 1993). Pre-transfer visits, though not previously addressed within the literature, were identified within the present research, as a means of determining appropriate patient allocation prior to transfer. In contrast, roles such as the ICU Liaison Nurse are involved in working with families and also ward staff, particularly with complex patients. By working with the wards the ICU Liaison Nurse understands the needs and workloads of the ward environment that then facilitates them to advise ICU of the appropriateness of the impending transfer (Barbetti \& Choate, 2003).

\section{Equipment}

Acquiring equipment, such as intravenous pumps, creates difficulties for ward staff. Often this is exacerbated by the limited number of intravenous pumps available within the clinical equipment pool within the hospital. Ward staff recognised that essential equipment needs to be accessed prior to patient transfer for continuity of patient care and safety. Whittaker and Ball (2000) note that prior knowledge of the appropriate equipment required prior to patient transfer was seen as paramount; another key aspect of effective communication as recognised within this research. The need to have the right equipment ready was perceived as a cause of stress by E Grade (advanced beginner/competent) nurses within Whittaker and Ball’s (2000) study. Consequently, knowledge and skills not only relate to caring for the ICU patient but also the appropriate use of medical equipment. Haines (2001) identified that acquiring and using appropriate medical equipment caused problems for ward staff, from locating intravenous giving sets and pumps, to nurses feeling 
unprofessional and scared when unable to operate equipment effectively. Whittaker and Ball (2000) suggest the reduction of non-essential monitoring prior to transfer; this can also apply to non-essential equipment. Assorted literature promotes the reduction of technological equipment at the bedside (Cutler \& Garner, 1995; Saarmann, 1993) in order to reinforce the indication that patients are progressing towards getting well and to reduce patients' and families' reliance on having monitors/equipment present in preparation for the ward.

\section{Continuity of patient care}

This research found documentation to be a continuation of patient care, particularly in relation to fluid balances and observation charts. This highlights the significance of transferring complete or partial shifts worth of patient data from the ICU 24-hour chart in order for ward nurses to fully comprehend the patient's most recent 24-hour history. Whittaker and Ball's (2000) study highlights that documentation is a crucial part of the transfer process that facilitates the patient's journey and helps ensure continuity of care. The overall organisation of paperwork was deemed by the participants to be important in order to access patient information in order to carry out immediate patient cares. Whittaker and Ball (2000) support this notion and advocate that fluid balance charts and observation charts should be readily accessible. Whittaker and Ball also point out that disorganised notes are timewasting and potentially place the patient at risk. Another piece of documentation that ward staff found useful in the Whittaker and Ball study "was the 'man with lines in' diagram that indicates the position of intravenous lines, sutures, catheters, and wound sites” (p. 139). Such diagrams exist on the assessment side of the 24-hour chart within ICU but are not currently part of transfer documentation for the wards. 
Previously unidentified within the literature is documentation surrounding medication charts. Medical documentation, such as patient's required medication not being transferred onto ward medication charts, PCA prescriptions not being charted and readily available for ward staff, or appropriate intravenous fluids not being charted prior to transfer. These tasks could be perceived as medical roles in which ICU nurses play a part in ensuring they are done as part of the transfer process. Again these processes can be perceived as time wasting for ward staff and potentially placing the patients at risk by not having the appropriate medical documentation readily available.

\section{Transfer forms}

Documentation as part of the transfer forms and within medical notes was considered insufficient within this research. It was recommended both within this research and as part of Whittaker and Ball's (2000) study that transfer forms should provide a summary of events outlining the main problems experienced by the patient. Although, recognising that transfer forms are only as thorough as the nurse completing them. Hall-Smith, Ball and Coakley (1997) ICU clinical practice group developed a similar form: an ICU summary sheet relevant to staff in wards and an assessment sheet outlining the ability of each patient and the care required in order to promote continuity of patient care by providing brief and relevant information.

Ideally, transfer forms should be directed at the next four to six hours of nursing care post-transfer to facilitate the ease of patient transition and nursing care as suggested within this research. Whittaker and Ball (2000) propose that ICU nurses may need to prescribe care for the initial 24 hours following transfer to provide ward 
staff with the information required to care for that patient, especially for junior staff unfamiliar with looking after patients who have been critically ill. A medical plan was considered important by this research to direct future care of the patient, though this should be standard practice as per ICU guidelines and is deemed a medical role not a nursing one. Documentation within the medical notes regarding nursing care performed was also deemed significant within this study, in order to plan and prioritise a patient's care, although it was not specifically noted within the literature.

\section{The other side of the transfer process}

Availability of suitable resources such as staffing levels and appropriately experienced staff on the wards is a common concern, a factor which ICU nursing staff tend to forget due to the nature of one-to-one nursing ratios, a diversity of experienced staff available during all shift patterns and the general isolation of ICU as a whole. Staffing levels on the wards fluctuate during different shifts, so there is more staff available in the mornings due the predicted 'busyness' of the shift, hence more support available and less staff rostered during the afternoons and at night. This creates concern for the wards as afternoon shifts often consist of junior staff when complex ICU patients get transferred to the ward. This may be complicated by the fact that often the afternoon co-ordinator is the only one who has relevant certifications to care for the ICU patient. Consequently, the availability of suitable staff and support to care for these patients is not always available.

Within this research senior staff acknowledged a concern for suitable staffing levels and appropriately experienced staff. This is acknowledged by Whittaker and 
Ball (2000) who also highlight overall ward safety and the effects that an ICU admission would have on other patients, as concerns of senior staff. Whittaker and Ball (2000) recognise that a lack of resources has an impact on inadequate staff being available to educate about the needs of the critically ill patient. This lack of resources is compounded further at night where further decreased staffing levels occur, lower nurse-patient ratios exist, which along with less medical and senior nursing support ultimately impact on patient care (Duke et al., 2004).

Experience of ward nurses impacts on patient allocation, a nurse's workload and the ease of receiving patients from ICU. Ward nurses identified that experience itself makes it easy to receive patients from ICU, in order to know what to look for and know what questions to ask. In contrast, less experienced staff tended not to question the ICU nurse's handover, a concept that Atwal (2002) recognises by suggesting that if nurses do not understand the information given they do not question it; potentially allowing adverse events to occur during a patient's hospital admission. Benner (1984) defines experience as the fine-tuning of preconceived ideas and theory through exposure to many real practical situations, where clinical practice is often more multifaceted. Often, it is experienced staff that are allocated to care for patients from ICU when available due to their specific knowledge base and clinical skills required to care for these patients (Haines, 2001), which ultimately impacts on their already busy and potentially heavy workload. Haines points out that it is the experience of the nurse that enables them to make professional judgements, such as whether or not to accept the patient from ICU.

Whittaker and Ball (2000) believe that education needs to be given not only to junior nurses in managing the complex needs of transferred ICU patients but also 
to ICU nurses to increase their awareness of the needs of ward nurses. This latter aspect is identified within this study where participants felt that ICU nurses needed to have a better understanding of the ward environment and their needs. This education of ICU nurses also needs to extend to discharge/transfer planning, an area in which ICU nurses are ill-equipped due to a lack of knowledge (Chaboyer et al., 2002; Watts et al., 2005). By improving ICU nurses’ knowledge of discharge/transfer planning and changing the nursing perception from discharge to transfer as well as the importance of communication, collaboration and understanding; the transfer process as a whole may improve.

Minimal reference was made to follow-up of patients within this research; nevertheless, it was identified that there is a lack of ICU involvement from the view that once patients are treated ICU is no longer involved in their care. This is particularly in relation to a lack of understanding of what ward staff can manage regarding knowledge/skill level and experience, where assumptions can be made and ICU does not always appreciate the ward situation. Poor communication between departments, along with a busy ward, a lack of knowledge/skills, and a lack of resources (experienced staff) can potentially lead to inadequate care on the wards (Russell, 1999). Russell emphasises that one of the key factors to re-admissions to ICU is inadequate follow-up on the general wards. Accordingly extended nursing roles such as CNS, ICU Liaison Nurse/ICU Discharge Nurse and ICU Follow-Up Nurses have been advocated to facilitate the continuity of patient care and support ward staff in caring for complex critically ill patients. This occurs either by being involved in coordinating efficient patient transfer, pre-transfer visits, ward follow-up or by providing clinical support to ward staff in order to ensure a smooth and safe transfer process (Chaboyer et al., 2005; Hall-Smith et al., 1997; Russell, 1999). 


\section{Families as a part of nursing care}

The provision of psychological support to patients and families by ward nurses has been documented as a problem within the literature (Haines, 2001; Whittaker \& Ball, 2000). A similar perception was revealed within this research regarding families. If anything, caring for patients and families was seen as a part of nursing care and not perceived as a cause of additional stress. As opposed to Cutler and Garner's (1995) study that found that ward nurses had "problems with patients initial lack of awareness and understanding of their workload and patient allocation” (p.334).

Ward nurses within this study identified that patients varied in their response to transfer depending on their level of illness; some considered them too unwell to express any concerns regarding being transferred, whereas others felt it took them awhile to adjust. This evidence differs from Haines’ (2001) study where ward nurses described patients expressing fear, apprehension, vulnerability, anxiety, and being frightened on transfer from the familiarity of ICU to the ward: themes that are associated with transfer anxiety or relocation stress as discussed within the literature review. In contrast, families were noted to be very nervous and anxious. Whittaker and Ball (2000) suggest that relatives experience anxiety associated with a decrease in nursing presence, whilst Haines also notes that the change in environment can come as a shock. This change in environment reflects the unknown where patients and families do not know what to expect, where different routines occur and treatment and monitoring can be different (Coyle, 2001; Leith, 1998; McKinney \& Melby, 2002; Saarmann, 1993). 
Despite the fact that ward nurses within this research did not overly perceive families to be a major issue for them, it was acknowledged that ICU could prepare families a little more. However, methods for preparing families were not elaborated. Pre-transfer teaching offers a way of sharing information about the patient transfer, creating an awareness of what to expect and preparing them for the changes in the care the patient will receive within a different environment. Recommendations within the literature include: relatives visiting the ward prior to patient transfer; introducing the family to ward staff (which already happens to some degree from CNL visits); including family in transfer planning; and transfer brochures/booklets (Cutler \& Garner, 1995; Haines, 2001; Mitchell \& Courtney, 2005c; Mitchell \& Courtney, 2005a; Mitchell \& Courtney, 2005b; Paul, Hendry, \& Cabrelli, 2003; Saarmann, 1993; Whittaker \& Ball, 2000). Interventions such as these can assist in reducing patients' and families' anxiety levels and builds early relationships with the ward. Overall, it is important to reinforce the transfer a progressive step toward recovery along with a positive picture of ward staff as a way of promoting continuity of care (Cutler \& Garner, 1995; Haines, 2001; Saarmann, 1993).

\section{Conclusion}

Communication is essential to any successful patient transfer and incorporates information sharing, the verbal handover and negotiating a suitable transfer time. However, information requirements of the ward nurse varies depending on their level of experience, although the underlying characteristic of the 'patient being as they say they are' exists for all ward nurses; this aspect was not addressed by scholars in the nursing literature. This concept maybe linked to knowing what to 
expect upon receiving the patient or simply not creating additional work for ward nurses. The verbal handover plays a crucial role in ensuring the continuity of patient care, a concept supported within the literature. However, ward nurses found an inadequate handover put them behind in their workload creating unnecessary frustration. The verbal handover process varied between nurses (bedside versus sit down or both); either way, sufficient time needs to be given to ensure a thorough patient handover. Delays in patient transfer were the only area that ward staff considered stressful at times, impacting on nursing and available nursing time: neither of these issues were highlighted within the literature.

Preparation is important for ward nurses when receiving patients from ICU, as this patient group requires more time and input. As part of this process it is imperative for ward staff to know about the patient, know what the patient needs and know what to expect upon receiving the patient. Pre-transfer visits by ward CNL are a way of assisting in this process and in determining appropriate patient allocation on the ward prior to transfer. Pre-transfer visits encourage familiarity with ward nursing staff and are a way of facilitating continuity of patient care. A common factor as part of preparation and communication was ensuring staff knew what equipment was required.

Continuity of care is related to the information about the patient's condition in order for the receiving ward to appropriately care for the patient. Documentation plays a crucial part in that process, particularly fluid balance charts, observation charts and transfer forms. Such documentation provides ward nurses with a clear picture of the patient's most recent history and treatment responses. Overall organisation of paperwork is essential to allow easy access to patient information in 
order to carry out immediate patient care. Disorganised paperwork can be time wasting for ward nurses and potentially put the patient at risk. Documentation as part of transfer forms was considered inadequate, whereby transfer documentation should provide a summary of events, outlining the main problems experienced by the patient whilst in ICU. Ward staff recognise that transfer forms need to be reviewed to address the needs of ward staff and potentially may need to direct the next 24 hours of nursing care to facilitate the continuity of patient care and assist less experienced ward staff.

Staffing levels and appropriately experienced ward staff are common concerns on the ward, which ICU nurses sometimes forget along with a lack of understanding of what wards can actually manage. Staffing levels on the wards vary during different shift patterns, with less nursing staff in the afternoons that consist of mostly junior staff. This impacts on the ability of wards to care for ICU patients once transferred due to their critical illness and complex needs. Therefore, the availability of suitable staff and support to care for these patients does not always exist. The availability of experienced ward nurses also impacts significantly on patient allocation, workload of nurses and their ability to receive patients from ICU. Consequently, education needs to be given to junior staff in managing the complex needs of the ICU patient and to ICU staff to increase their awareness of the needs of ward nurses, particularly in regard to what wards can actually manage in terms of knowledge, clinical skills and experience. Accordingly, extended roles such as an ICU liaison nurse/discharge nurses or CNS may have a place in facilitating the continuity of patient care and supporting ward staff. 
Although ward nurses do not consider families an additional stress they were very much considered a part of nursing care, which often includes providing psychological support. Families often experience anxiety due to decreased nursing presence in the wards, a change in environment, or different routines and treatment. Whereas patients responded differently to the transfer process depending on their level of illness, for some it takes time to adjust. Ward nurses have the added responsibility to reassure the family that the patient is in a safe environment. ICU nurses can support this process by reinforcing that transfer is a positive step towards recovery, along with a positive picture of ward staff as a way of promoting continuity of care. ICU can prepare patients and families more through pre-transfer teaching, so they know what to expect and prepare them for the changes in the care the patient will received within a different environment. 


\section{Chapter 7: Conclusion and Recommendations}

An exploratory descriptive methodology was used to explore the experiences of ward nurses receiving patients from ICU within the study site hospital. This research contributes to previous literature that has been written regarding the experiences of ward nurses receiving patients from ICU and the essential role that nurses play in the transfer process as a means of ensuring continuity of care. This research reiterates the significance of communication, documentation, continuity of patient care and appropriate resources but also highlights that nurses' perceptions can be different based on their focus of care. The knowledge gained from this research may provide better understanding of the multifaceted issues linked with transitional care that may be adaptable for a wider range of patients, in various clinical environments.

Communication is the paramount factor that impacts on a 'smooth transition' for ward nurses within this research. A 'smooth transition' refers to the transfer of patients from ICU to the next level of care; a more appropriate framework for ward and ICU nurses to work within. Subsequently, nurses’ perceptions need to change, whereby transfer planning from ICU should be the focus rather than discharge planning. Transfer planning and education for all nursing staff is vital if the transfer process is to be improved. Consequently, transitional care within the context of ICU aims to ensure minimal disruption and optimal continuity of care for the patient.

Whatever communication processes occur between wards/departments, the accentuating aspect is ensuring continuity of patient care, whereby the provision of information about the patient's condition enables the receiving department to 
appropriately care for that patient. However, information requirements of ward nurses and departments may vary depending on the individual's perception or focus of patient care, whereby individual nurses/departments have a different focus depending on the care context they work within. Consequently, nurses within this research recognise the need for better understanding between areas, in particular an understanding of what each ward/department does, and their workload issues.

Ultimately nurses are the primary health professionals involved in experiences with patients and their families in transitional periods of instability associated with health related illness changes. As patients are often transferred more than once during their hospital admission, each transition symbolises unique challenges for patients, their families, the nurses involved in their care and the health-care organisation. 'Models of care delivery' must take into account these transitional periods within a patient's journey to ensure optimal patient care, minimise gaps within that care continuum, and the impact multiple transitions have on patients and their families.

'Models of care delivery' or new ways of thinking may also need to take into account the changing nature of the acute care hospital environment and the impact acute care has on nurses in regard to managing safe staffing levels; workload allocation; managing higher acuity patients; patient allocation; providing extended care to families; providing education and support to staff to care for these critically ill patients; and their ability to receive patients from other areas. As well as the impact on the health-care organisation in managing patient flow/movement efficiently; allocation of appropriate resources; health-care planning that takes into 
account 'transitional care' across the organisation; and overall cost to the organisation.

\section{Recommendations for clinical practice}

The nurses stated that they felt ICU nurses forget what it is like in the ward environment. In light of this it may be useful for a mechanism to be established so that transfer processes and experiences can be shared between ICU staff and ward staff. In this way recommendations for practice change to enhance patient outcomes can be developed jointly.

It is recommended that a shared collaborative 'think tank' process occurs to gain multiple perspectives on new ways to facilitate the transition of patients from ICU to the ward to ensure continuity of patient care and improve communication process between ICU and the ward involving ICU nurses, ward nurses, patients and families.

Ward nurses stated that transfer forms did not cover everything the ward needed to know. In view of this it is recommended that a clinical practice group be established to review of all three transfer forms (general, cardiac, paediatric) in consultation with the wards to ensure relevant information required by the wards is given, to ensure continuity of patient care.

The nurses described documentation as inadequate, particularly documentation of fluid balance charts and previous patient vital signs. It is 
recommended that a collaborative process between the wards and ICU occur to establish the relevant documentation required in these areas and to look at ways that this may be best achieved, in order to ensure continuity of patient care.

Ward nurse felt that pre transfer visits by ward CNL was useful as part of the preparation process. In light of this it is recommended that a mechanism be established to address the feasibility of all ward CNL conducting pre-transfer visits to ICU prior to patient transfer. Pre-transfer visits would assist ward staff in knowing what to expect and allows them to prepare for receiving the patient from ICU. This process would also allow the ward to allocate suitably experienced staff to care for that patient and determine overall acuity and therefore plan nursing workloads.

It is recommended that there is the potential to explore the development of extended roles such as an ICU Discharge/Liaison Nurse to coordinate/oversee the transition of patients from ICU to the general wards, with involvement in activities such as a ward liaison, patient care and support, ward staff support and family education and support. Such a role would assist in networking between different areas, improve understanding of different workload pressures and assist in breaking down perceived barriers between ICU and the ward.

It is recommended that a shared collaborative process occur between bedside nurses, CNL, nursing management, clinical services and hospital management to review the pathways/systems in place that relate to patient 
movement/transition within the organisation - i.e. transition in and transition out of intensive care/wards. In order to achieve health-care outcomes such as seamless care, reduced ICU re-admissions, continuity of care, customer satisfaction, decreased length of hospital stay; where a person-centred approach can be utilised to develop new pathways of care that are centred around patient-ownership and improving patient flow/movement.

\section{Recommendations for nursing research}

It is recommended that further research be done in exploring the experiences and challenges for ward nurses in receiving patients from ICU due to the limited nursing literature available.

It is recommended that further research that involves paediatrics nurses occur due to the unique nature of the paediatric population within an adult ICU and paediatric nurses being unable to attend the focus group discussions at the time due to ward commitments.

It is recommended that the findings from this research be utilised to conduct a wider study, using a different methodology, of all ward nurses experiences of receiving patients from ICU within the study setting hospital.

It is recommended that this research be further utilised to examine the transition of patients from ICU to the ward from an ICU nurses perspective. 
It is recommended that nursing research that utilises focus groups are explicit in their written reports to add to the body of knowledge about what works and does not work whilst conducting focus group research.

\section{Limitations}

The limitations of this research relate to the relatively small focus group sizes, which may potentially have made the study vulnerable to internal validity despite processes put in place to ensure this. The relatively small sample size may also represent only a proportion of ward nurses' experiences and concerns when receiving patients from ICU. Consequently, further research using the information from this research could be used to conduct a wider study of ward nurses that receive patients from ICU within the study site.

Theoretical generalisation of these findings can occur (Sim, 1998), where the findings can be projected to other contexts that are comparable to the original study. More commonly known as transferability, where it is the receiver of the research who decides if the results can be applied to another context (Krueger \& Casey, 2000). Hence, the findings from this research can generally be transferred to all ward nurses receiving patients from ICU within the study setting hospital, at this point in time with the recognition that diverse specialities having different concerns as noted in the findings. 


\section{Appendices}

Appendix I: Clinical Nurse Leader letter

Appendix II: Flyer

Appendix III: Observer Confidentiality Form

Appendix IV: Information sheet/Consent form

Appendix V: Northern Y Regional Ethics Committee

Appendix VI: Kaumatua Kaunihera Committee 


\section{Appendix I: Clinical Nurse Leader letter}

1A Sunnyside Road

Hamilton 3200

$7^{\text {th }}$ August 2006.

Clinical Nurse Leaders/Educators

Dear Colleagues,

I am a Masters (Clinical) Nursing student studying through Victoria University, Wellington. Part of my course requirements for this year involves completing a thesis, a piece of scholarly work, which contributes to the discipline of nursing. This entails a small research project.

My research is entitled:

'Transition of patients from intensive care to the ward: a ward nurses' perspective'.

The aim of this research is to explore the transition of patients from intensive care to the ward environment from a ward nursing perspective. In doing so I hope to contribute to improving nursing transfer documentation, address what information is pertinent for ward nurses upon patient transfer and facilitate a smoother transition process. This research involves the participation of ward nurses in focus groups to share their opinions, ideas, experience and insight into this research topic. The participation of ward nurses is voluntarily. I would like to be able to put up flyers within your area to invite nurses to participate in this study.

This research is supervised by Professor Ken Walsh, Graduate School of Nursing \& Midwifery, Victoria University, Wellington and has gained ethical approval from the Northern Y Regional Ethics Committee.

If you would like more information about the research please do not hesitate to contact me. A copy of the Ethics Application and Research Proposal are available upon request. I appreciate your support in my nursing thesis.

Sandra Bunn

Masters (Clinical) Nursing Student

Graduate School of Nursing \& Midwifery

Victoria University Wellington

Mobile: 0276646408

E-mail: sandra.bunn@clear.net.nz 


\title{
Appendix II: Flyer
}

VICTORIA UNIVERSITY OF WELLINGTON

Te Whare Wananga o te Upoko o te Ika a Maui

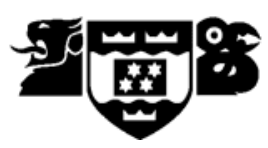

An invitation to participate in nursing research:

\section{TRANSFER OF PATIENTS FROM}

\section{INTENSIVE CARE TO THE WARD:}

\section{A WARD NURSES’ PERSPECTIVE.}

\author{
Are you interested in sharing your experiences \\ Would you like to share your ideas/opinions \\ What information would be appropriate upon patient transfer \\ Do you think the transfer process could be changed
}

If you would like to participate in focus group discussion regarding this research please contact the researcher at any time to ask questions or discuss this research in further detail.

\author{
Researcher: \\ Sandra Bunn \\ Masters (Clinical) Nursing Student \\ Victoria University Wellington \\ Ph: 078491555 \\ Mobile: 0276646408 \\ E-mail: sandra.bunn@clear.net.nz
}




\section{Appendix III: Observer Confidentiality Form}

\section{Title of Research:}

'Transition of patient from intensive care to the care: A ward nurses' perspective'.

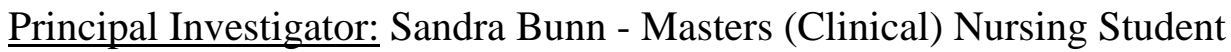

Name of Observer:

\section{Position:}

Contact Details:

I have read the and understood the information sheet for participants taking part in this study, designed to explore the experiences and issues for ward nurses when receiving patients from intensive care. I understand that this research is being done as part of a Nursing Masters and is being supervised.

I have had the opportunity to discuss this research with the investigator and am satisfied with the answerers I have been given.

I understand that participants' participation in this study is confidential and anonymous and that no information or material is to be discussed beyond the boundaries of the focus group other than direct discussions with the researcher.

I understand that the field notes I take during the focus group session will be used as part of the data collection within the study.

I understand that the focus group sessions are being audio taped as back up and will not be transcribed.

I understand that the Northern Y Regional Ethics Committee have approved this research.

Signature of Observer:

Date:

Signature of Researcher:

Date: 


\section{Appendix IV: Information Sheet/Consent form}

Research Title: An exploration of the transition of patients from intensive care to the ward environment: a ward nursing perspective.

Researcher: Sandra Bunn, RN, PG Cert (ICU), Masters (Clinical) Nursing Student

Graduate School of Nursing, Midwifery \& Health

Victoria University, Wellington.

Phone: 078491555

Mobile: 0276646408

E-Mail: sandra.bunn@clear.net.nz

Supervisor: Ken Walsh, Clinical Professor of Nursing. Nursing Research \& Development Unit, Waikato Hospital Graduate School of Nursing, Midwifery \& Health, Victoria University, Wellington. E-Mail: walshk@waikatodhb.govt.nz

\section{Background:}

This research project has come about due to anecdotal evidence in the transition of patients from the Intensive Care Unit (ICU) to the ward environment. This process can create enormous anxiety, stress and fear for patient and families alike. As well as anxiety and stress on the part of the receiving ward staff. It is recognised that nurses play an essential role in the transition process to ensure continuity of patient care, decrease transfer anxiety in patients and families alike and can enhance communication channels between areas.

\section{Aim:}

The aim of this research is to explore the transition of patients from intensive care to the ward environment from a ward nursing staff perspective.

\section{Objectives:}

- To explore the experiences of ward staff when receiving patients from ICU

- To identify any issues/concerns that occurs when receiving patients from ICU

- To highlight specific problems that occurs on transition from ICU to the ward

- To address what information is pertinent to ward nurses upon transfer. 
Participation in this research may not be of direct benefit to you, though the information gained through this study may contribute to improving the transition of patients from intensive care to the ward and ensure continuity of patient care. It has the potential to contribute to enhancing communication and networking between wards, in order to understand the complex needs of nursing staff in looking after high acuity patients transferred from intensive care.

What will you be required to do: You will be asked to participate in focus group discussions for approximately 60 - 90 minutes. These discussions will be taped as a back up, but will not be transcribed and field notes taken. A second person (neutral) will be present to take notes and facilitate discussion. This person will complete a confidentiality agreement.

All participants will sign an informed consent. Information will remain confidential to the researcher and their supervisor. It will not be possible to identify you in any reports that are prepared from the focus groups. 


\section{CONSENT FORM:}

I have read the information provided to me for this focus group and have had the opportunity to discuss it with Sandra Bunn.

I am satisfied with the answers I have been given. I understand that I may ask further questions at any time.

I understand that I have the right to participate voluntarily, the right to withdraw at any time and the right not to respond to any questions during the focus group.

I understand that a neutral observer may attend and that they have signed a confidentiality agreement.

Please indicate which ethnic group you affiliate with as per the Health \& Disability Sector (Ministry of Health, 2004).

$\begin{array}{ll}\square \text { New Zealand European } & \square \text { Tongan } \\ \square \text { Maori } & \square \text { Niuean } \\ \square \text { Samoan } & \square \text { Chinese } \\ \square \text { Cook Island Maori } & \square \text { Indian }\end{array}$

$\checkmark$ Other If other please state

I understand that any information that I provide will be kept confidential to the researcher and supervisor and that no material which could identify me will be used in this research thesis. Confidentiality is encouraged within the focus group discussions but cannot be assured. I understand that that the tape recording of the focus groups will be kept for a minimum of five years and the raw data indefinitely.

I understand that the Northern $\mathrm{Y}$ Regional Ethics committee has approved the research.

Please indicate whether you wish to receive an overall summary of the Focus Group discussion. YES NO

If yes please provide contact details at the bottom of the page.

Statement by participant: I hereby consent to take part in this study.

Name of Participant:

Signature of participant:

Date:

Signature of Researcher:

Date:

Contact details if appropriate: 


\section{Appendix V: Northern Y Regional Ethics Committee}

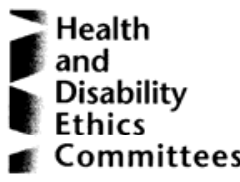

\author{
Northern Y Regional Ethics Committee \\ Ministry of Health

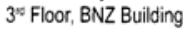 \\ 354 Victoria Street \\ PO Box 1031 \\ Hamilton \\ Phone (07) 8587021 \\ Fax (07) 8587070
}

\section{July 2006}

Ms Sandra Bunn

1A Sunnyside Road

Nawton, Hamilton

Dear Sandra

An exploration of the transition of patients from intensive care to the ward environment: a ward nursing perspective.

Ms Sandra Bunn

Waikato Hospital

NTY/06/05/042

The above study has been given ethical approval by the Northern Y Regional Ethics Committee.

\section{Approved Documents}

Focus group Information Sheet and Consent form

Observer Confidentiality Form

\section{Accreditation}

The Committee involved in the approval of this study is accredited by the Health Research Council and is constituted and operates in accordance with the Operational Standard for Ethics Committees, March 2002.

\section{Final Report}

The study is approved until 28 March 2007. A final report is required at the end of the study and a form to assist with this is available from the Administrator. If the study will not be completed as advised, please forward a progress report and an application for extension of ethical approval one month before the above date. Report forms are available from the administrator.

\section{Amendments}

It is also a condition of approval that the Committee is advised of any adverse events, if the study does not commence, or the study is altered in any way, including all documentation eg advertisements, letters to prospective participants.

Please quote the above ethics committee reference number in all correspondence.

It should be noted that Ethics Committee approval does not imply any resource commitment or administrative facilitation by any healthcare provider within whose facility the research is to be carried out. Where applicable, authority for this must be obtained separately from the appropriate manager within the organisation.

Yours sincerely

$$
\operatorname{lox} \operatorname{lich}
$$

Amrita Kuruvilla

Northern Y Ethics Committee Administrator

Email: amrita_kuruvilla@moh.govt.nz 


\section{Appendix VI: Kaumatua Kaunihera Committee}

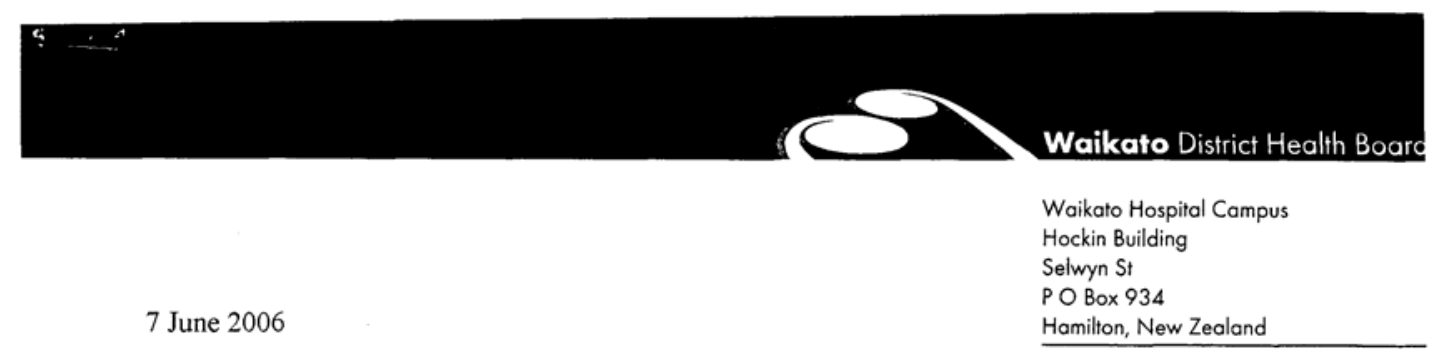

7 June 2006

Hamilton, New Zealand

Sandra Bunn

Staff Nurse

Intensive Care Unit

Waikato District Health Board

Private Bag 3200

HAMILTON

Tena koe Sandra,

AN EXPLORATION OF THE TRANSITION OF PATIENTS FROM INTENSIVE CARE TO THE WARD ENVIRONMENT: A WARD NURSES' PERSPECTIVE

Thank you for submitting research material to the Kaumatua Kaunihera Ethics Sub-committee. The Sub-committee is pleased to have the opportunity to provide feedback. Issues discussed in our meeting include:

- An ethnicity data collection space should be included on the participant consent form as per the Ethnicity Data Protocols for the Health and Disability Sector (Ministry of Health, 2004);

- Please see the attached for a discussion on ensuring that the results of your research are equally applicable to Mãori and non-Mãori.

The Kaumatua Kaunihera Ethics Sub-committee supports your research. Should you have any queries regarding our feedback, please contact me

Noho ora mai,

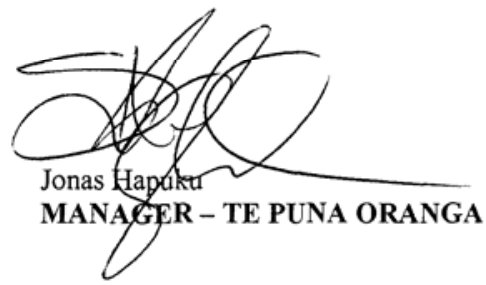


Suggestions to ensure that the results are equally applicable to Maori

To ensure that the results are equally applicable to Maori as well as Non-Maori it is important that Maori are given an opportunity to participate equally at all levels of the research. Ways of doing this include the following;

- Ensure that equal numbers of the participants are Maori and Non-Maori.

- Have Maori and Non-Maori focus groups, and facilitators.

- Explore the experiences of ward staff (both Maori and Non-Maori) when receiving Maori patients from ICU, and Non-Maori patients from ICU. A 4x4 table could be useful.

\begin{tabular}{lll|l|} 
& & \multicolumn{2}{c}{ Patients } \\
Nurses & & \multicolumn{1}{c}{ M } & N-M \\
\cline { 3 - 4 } & $\mathrm{M}$ & $\mathrm{A}$ & $\mathrm{B}$ \\
\cline { 3 - 4 } & $\mathrm{N}-\mathrm{M}$ & $\mathrm{C}$ & $\mathrm{D}$ \\
\cline { 3 - 4 } & & &
\end{tabular}

$A=$ experiences of Maori ward staff when receiving Maori patients from ICU

$\mathrm{B}=$ experiences of Non-Maori ward staff when receiving Maori patients from ICU

$\mathrm{C}=$ experiences of Maori ward staff when receiving Non-Maori patients from ICU

$\mathrm{D}=$ experiences of Non-Maori ward staff when receiving Non-Maori patients from ICU

Please note that the above are suggestions only. 


\section{References}

Anderson, M. A., \& Helms, S. (1994). Quality improvement in discharge planning: An evaluation of factors in communication between healthcare providers. Journal of Nursing Care Quality, 8, 62-72.

Atwal, A. (2002). Nurses' perceptions of discharge planning in acute health care: A case study in one British teaching hospital. Journal of Advanced Nursing, 39(5), 450-458.

Ball, C. (2005). Ensuring a successful discharge from intensive care. Intensive \& Critical Care Nursing, 21, 1-4.

Barbetti, J., \& Choate, K. (2003). Intensive care liaison nurse service: Implementation at a major metropolitan hospital. Australian Critical Care Journal, 16(2), 46-52.

Benner, P. (1984). From expert to novice - excellence and power in clinical nursing practice. California: Addison-Wesley Publishing Company.

Benner, P., Hooper-Kyriakidis, P., \& Stannard, D. (1999). Clinical Wisdom and Interventions in Critical Care - a thinking in action approach. United States of America: W.B. Saunders Company.

Beyea, S. C., \& Nicoll, L. H. (2000). Learn more using focus groups. Association of Operating Room Nurses, 71(4), 897-900.

Bixby, M. B., Konick-McMahon, J., \& Mckenna, C. G. (2000). Applying the transitional care model to elderly patients with heart failure. Journal of Cardiovascular Nursing, 14(3), 53-63.

Bonvissuto, C. A. (1994). Avoiding unnecessary critical care costs. Healthcare Financial Management, 48(11), 47-50.

Bromley, P. (2000). Transitional care:Lets think again. Journal of Neonatal Nursing, 6(2), 60-64.

Brown, S. J. (1999). Knowledge for health care practice: A guide to using research evidence. Philadelphia: W.B. Saunders Company.

Brzozowski, L. A. (1998). Transitional Care. AACN Clinical Issues, 9(3), 396-397.

Carpenito, L. J. (2002). Nursing diagnosis: Application to clinical practice. (9th ed.). Philadelphia: Lippincott

Carr, P. (1988). Discharge planning: A critical care responsibility. Critical Care Nurse, 8(5), 78-81. 
Chaboyer, W., Tahalib, L., Foster, M., Elliott, D., Endacott, R., \& Richards, B. (2006). The impact of an ICU Liaison Nurse on discharge delay in patients after prolonged ICU stay. Anesthesia and Intensive Care, 34(1), 55-60.

Chaboyer, W., Foster, M., Kendall, M., \& James, H. (2002). ICU nurses' perceptions of discharge planning: A preliminary study. Intensive \& Critical Care Nursing, 18, 90-95.

Chaboyer, W., Foster, M. M., Foster, M., \& Kendall, E. (2004). The intensive care unit liaison nurse: Towards a clear role description. Intensive \& Critical Care Nursing, 20, 77-86.

Chaboyer, W., Foster, M., Kendall, M., \& James, H. (2004). The impact of a liaison nurse on ICU nurses' perceptions of discharge planning. Australian Critical Care Journal, 17(1), 25-32.

Chaboyer, W., James, H., \& Kendall, M. (2005). Transitional care after the intensive care unit: Current trends and future directions. Critical Care Nurse, 25(3), 16-28.

Coombs, M. (2001). Towards collaborative and collegial caring: A comparative study. Nursing in Critical Care, 6(1), 23-27.

Coyle, M. A. (2001). Transfer anxiety: Preparing to leave intensive care. Intensive and Critical Care Nursing, 17, 138-143.

Creswell, J. W. (2003). Research design qualitative, quantitative and mixed method approaches. ( ${ }^{\text {nd }}$ ed.). London: Sage Publications.

Cutler, L., \& Garner, M. (1995). Reducing relocation stress after discharge from the intensive therapy unit. Intensive \& Critical Care Nursing, 11, 333-335.

Daffurn, K., Bishop, G. F., Hillman, K. M., \& Bauman, A. (1994). Problems following discharge after intensive care. Intensive and Critical Care Nursing, 10, 244-251.

Dawson, J. A. (1993). Admission, discharge and triage in critical care. Critical Care Clinics, 9(3), 555-575.

Department of Health. (2000). Comprehensive Critical Care: A review of adult critical care services. London: Department of Health.

Duddridge, E. (2001). Neonatal issues: What are the advantages of transitional care for neonates? British Journal of Midwifery, 9(2), 92-99.

Duke, G., Green, J. V., \& Briedis, J. H. (2004). Night-shift discharge from intensive care increases the mortality-risk of ICU survivors. Anesthesia and Intensive Care, 32(5), 697-701. 
Giannini, A., Consonni, D. (2006). Physicians' perceptions and attitudes regarding inappropriate admission and resource allocation in the intensive care setting. British Journal of Anesthesia, 96(1), 57-62.

Glanze, W. D. (Ed.). (1990). Mosby's medical, nursing and allied health dictionary. (3rd ed.). St. Louis: C.V. Mosby Company.

Goldfrad, C., \& Rowan, K. (2000). Consequences of discharges from intensive care at night. The Lancet, 355, 1138-1142.

Grbich, C. (1999). Qualitative Research In Health. Australia: Allen \& Unwin Pty Ltd.

Green, A., \& Edmonds, L. (2004). Bridging the gap between the intensive care unit and the general ward - the ICU Liaison Nurse. Intensive \& Critical Care Nursing, 20, 133-143.

Griffin, K. M. (1998). Evolution of transitional care settings: Past, present, future. AACN Clinical Issues, 9(3), 398-408.

Griffiths, R. D., \& Jones, C. (2002). Intensive Care Aftercare. Oxford: Butterworth-Heinemann.

Haines, S. (2001). Providing continuity of care for patients transferred from ICU. Professional Nurse, 17(1), 17-21.

Haines, S., \& Coad, S. (2001). Supporting ward staff in acute care areas: Expanding the service. Intensive \& Critical Care Nursing, 17, 105-109.

Hall-Smith, J., Ball, C., \& Coakley, J. (1997). Follow-up services and the development of a clinical nurse specialist in intensive care. Intensive \& Critical Care Nursing, 13, 243-248.

Hamer, H. P., \& McCallin, A. M. (2006). Research article; cardiac pain or panic disorder? Managing uncertainty in the emergency department. Nursing and Health Sciences, 8(4), 244.

Havill, J. H., \& Lawrence, A. (1999). An audit of deaths occurring hospital after discharge from the intensive care unit. Anesthesia and Intensive Care., 27(2), 185-189.

Heidegger, C., Treggoaro, M. M., \& Romand, J. (2005). A nationwide survey of intensive care unit discharge practices. Intensive Care Medicine, 31, 16761682.

Higlett, T., Bishop, N., Hart, G. K., \& Hicks, P. (2005). Review of intensive care resources an activity 2002/2003. Melbourne: ANZICS.

Howard, E., Hudelbank, J. H., \& Moore, P. S. (1989). Employer evaluation of graduates: Use of the focus group. Nurse Educator, 14(5), 38-41. 
Intensive Care Clinical Advisory Group. (2005). Intensive care unit services in New Zealand: A report to the Deputy Director-General Clinical Services. Wellington: Ministry of Health.

Johnson, B., \& Turner, L. A. (2003). Data collection strategies in mixed methods research. In A. T. Tashakkori, C. (Ed.), Handbooks of mixed methods in social and behavioral research. Thousand Oaks: Sage Publications Ltd.

Jones, A. M., \& Foster, N. (1997). Transitional care: Bridging the gap. Medsurg Nursing, 6(1), 32-38.

Jones, C., \& O'Donnell, C. (1994). After intensive care - what then? Intensive and Critical Care Nursing, 10, 89-92.

Krueger, R. A. (1994). Focus Groups: A practical guide for applied research (2nd. ed.). Thousand Oaks. California: Sage Publications Ltd.

Kruger, R. A. (1998). Analyzing and reporting focus group results. Thousand Oaks, California: Sage Publications Inc.

Krueger, R. A., \& Casey, M. A. (2000). Focus Groups: A practical guide for applied research. (3rd. ed.). Thousand Oaks, California: Sage Publications, Inc.

Lasby, K., Newton, S., \& Von Platen, A. (2004). Neonatal transitional care. Canadian Nurse, 100(8), 18-23.

Leith, B. A. (1998). Transfer anxiety in critical care patients and their family members. Critical Care Nurse, 18(4), 24-32.

Madriz, E. (2000). Focus groups in feminist research. In N. K. Denzin \& Y. S. Lincoln (Eds.), Handbook of qualitative research (2nd ed.). Thousand Oaks, California: Sage Publications Ltd.

Massey, C. J., Dino, G. A., Horn, K. A., Lacey-McCraken, A., Goldcamp, J., \& Kalsekar, I. (2003). Recruitment barriers and successes of the American Lung Association's Not-On-Tobacco Program. Journal of School Health, 73(2), 5863.

McGinley, S., Baus, E., Gyza, K., Johnson, K., Lipton, S., Magee, M. C., et al. (1996). Multidisciplinary discharge planning - developing a process. Nursing Management, 27(55), 57-60.

McKinney, A. A., \& Melby, V. (2002). Relocation stress in critical care: A review of the literature. Journal of Clinical Nursing, 11, 149-157.

McLafferty, I. (2004). Focus group interviews as a data collecting strategy. Journal of Advanced Nursing, 48(2), 187-194. 
Meleis, A. I., Sawyer, L. M., Im, E., Messias, D. K. H., \& Schumacher, K. (2000). Experiencing transitions: An emerging middle-range theory. Advanced Nursing Science, 23(1), 12-28.

Mertens, D. M. (2003). Mixed methods and the politics of human research: The transformative-emancipatory perspective. In A. Tashakkori \& C. Teddlie (Eds.), Handbook of mixed methods in social \& behavioral research. Thousand Oaks, California: Sage Publishers, Inc.

Ministry of Health. (2004). Ethnicity data protocols for the health and disability Sector. Wellington: Ministry of Health.

Mitchell, M. L., \& Courtney, M. (2005a). Improving transfer from the intensive care unit: The development, implementation and evaluation of a brochure based on Knowles' adult learning theory. International Journal of Nursing Practice, 11, 257-268.

Mitchell, M. L., \& Courtney, M. (2005b). An intervention study to improve the transfer of ICU patients to the ward - evaluation by family members. Australian Critical Care Journal, 18(2), 61-69.

Mitchell, M., \& Courtney, M. (2005c). An intervention study to improve the transfer of ICU patients to the ward - evaluation by ICU nurses. Australian Critical Care Journal, 18(3), 123-128.

Morgan, D. L. (1996). Focus groups. Annual Review of Sociology, 22, 129-152.

Morgan, D. L. (1997). Focus groups as qualitative research (2nd ed.). California: Sage Publications, Inc.

Naylor, M. D. (2000). A decade of transitional care research with vulnerable elders. Journal of Cardiovascular Nursing, 14(3), 1-14.

Nyamathi, A., \& Schuler, P. (1990). Focus group interview: A research technique for informed nursing practice. Journal of Advanced Nursing, 15, 1281-1288.

Odell, M. (2000). The patient's thoughts and feelings about their transfer from intensive are to the general ward. Journal of Advanced Nursing, 31(2), 322329.

Paul, F., Hendry, C., \& Cabrelli, L. (2003). Meeting patient and relatives' information needs upon transfer from an intensive care unit: The development and evaluation of an information booklet. Journal of Clinical Nursing, 13, 396-405.

Ridley, S. A. (1998). Intermediate care: Possibilities, requirements and solutions. Anesthesia, 53, 654-664.

Roberts, K., \& Taylor, B. (2002). Nursing research processes: An Australian perspective. (2nd ed.). Southbank Victoria: Nelson. 
Rowe, W. E. (2001). An ethnography of the nursing handover. Unpublished master's thesis, Massey University, Albany: Auckland

Rudolph Durrie, K. (2002). Neonatal transitional care program. Alberta RN, 58(11), 4-5.

Russell, S. (1999). Reducing readmission to the intensive care unit. Heart \& Lung, 28(5), 365-372.

Saarmann, L. (1993). Transfer out of critical care: Freedom or fear? Critical Care Nurse Quarterly, 16(1), 78-85.

Sandelowski, M. (2000). Focus on research methods: Whatever happened to qualitative description? Research in Nursing \& Health, 23, 334-340.

Schlemmer, B. (1989). The status of discharge planning in intensive care units. Nursing Management, 20(7), 88a-88p.

Schumacher, K., \& Meleis, A. I. (1994). Transitions: A central concept in nursing. IMAGE: Journal of Nursing Scholarship, 26(2), 119-127.

Schumaker, G. L., Hill, N. S., \& Garpestad, E. (2005). A looming crisis in demand for intensive care unit resources? Critical Care Medicine, 33(3), 683-684.

Sim, J. (1998). Collecting and analyzing qualitative data: Issues raised by the focus group. Journal of Advanced Nursing, 28(2), 345-352.

Society of Critical Care Medicine. (1999). Guidelines for ICU admission, discharge, and triage. Critical Care Medicine, 27(3), 633-638.

Strahan, E. H. E., \& Brown, R. J. (2005). A qualitative study of the experiences of patients following transfer from intensive care. Intensive and Critical Care Nursing, 21, 160-171.

Strosberg, M. A. (1993). Intensive care units in the triage mode: An organisational perspective. Critical Care Clinics, 9(3), 415-424.

Van Waning, N. R., Kleiber, C., \& Freyenberger, B. (2005). Development and implementation of a protocol for transfers out of the paediatric intensive care unit. Critical Care Nurse, 25(3), 50-55.

Walsh, J., Moss, C., Fitzgerald, M. (2006). Solution- focused approaches and their relevance to practice development. Practice Development in Health Care, 5(3), 145-155.

Watts, R. J., Gardner, H., \& Pierson, J. (2005). Factors that enhance or impede critical care nurses' discharge planning practices. Intensive \& Critical Care Nursing, 21, 302-313. 
Watts, R. J., Pierson, J., \& Gardner, H. (2005b). How do critical care nurses define the discharge planning process? Intensive \& Critical Care Nursing, 21, 3946.

Webb, B. (2002). Using focus groups as a research method: A personal experience. Journal of Nursing Management, 10, 27-35.

Webster, J. (1999). Practitioner-centered research: An evaluation of the implementation of the bedside hand-over. Journal of Advanced Nursing, 30(6), 1375-1382.

Whittaker, J., \& Ball, C. (2000). Discharge from intensive care: A view from the ward. Intensive and Critical Care Nursing, 16, 135-143.

Williams, T., \& Leslie, G. (2004). Delayed discharges from an adult intensive care unit. Australian Health Review, 28(1), 87-96. 